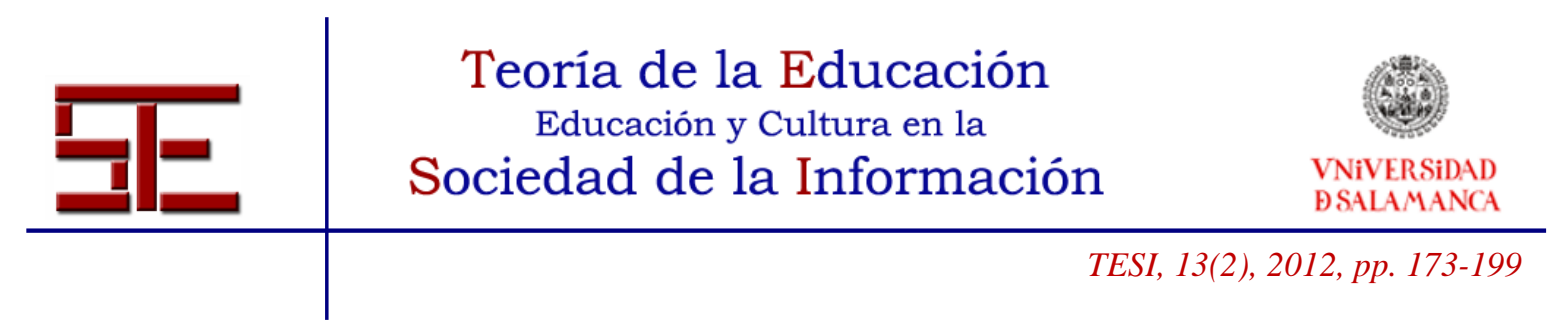

\title{
PERCEPCIONES DE LOS FUTUROS DOCENTES SOBRE LA CULTURA ORGANIZACIONAL DE LOS CENTROS DE PRÁCTICAS EXTERNAS DE EDUCACIÓN SECUNDARIA
}

Resumen: El objetivo general del presente trabajo es aportar los resultados iniciales de pasar un cuestionario sobre cultura organizacional en los Centros de Educación Secundaria a 57 futuros docentes estudiantes del Máster Universitario en Profesorado de Educación Secundaria Obligatoria y Bachillerato, Formación Profesional y Enseñanza de Idiomas por la Universidad de Málaga correspondientes a la especialidad de Tecnología, Informática y Procesos Industriales. Los resultados demuestran que el profesorado principiante considera que el profesorado debe realizar su docencia teniendo en cuenta la diversidad del alumnado en su aula, revisar sus técnicas y estrategias didácticas en proceso de formación y actualización permanente. Se encuentran además diferencias en la percepción de la cultura organizacional de los Centros de Educación Secundaria en función del género en lo que respecta a variables relacionadas con las funciones de la Institución, el gobierno de los centros, la financiación, la metodología, el alumnado, la evaluación y las relaciones con el entorno. Los datos obtenidos son útiles para la mejora de las acciones de formación necesarias, evaluación de posibles sesgos al respecto y su adaptación a los retos y desafíos que tiene planteada la Educación Secundaria.

Palabras clave: Máster universitario; Prácticum; cultura organizacional; género; Educación Secundaria.

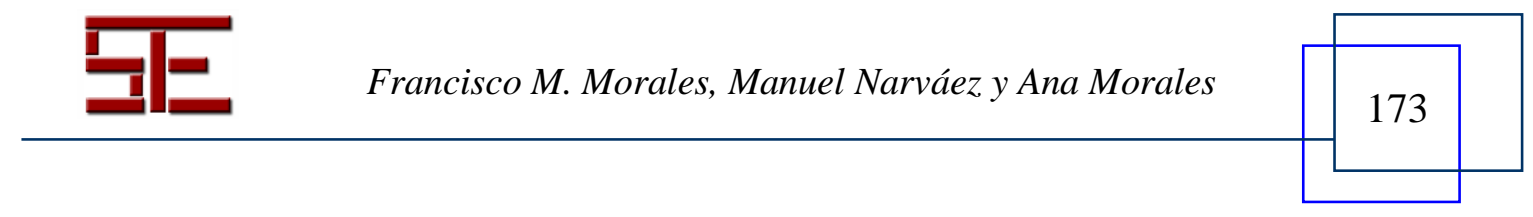




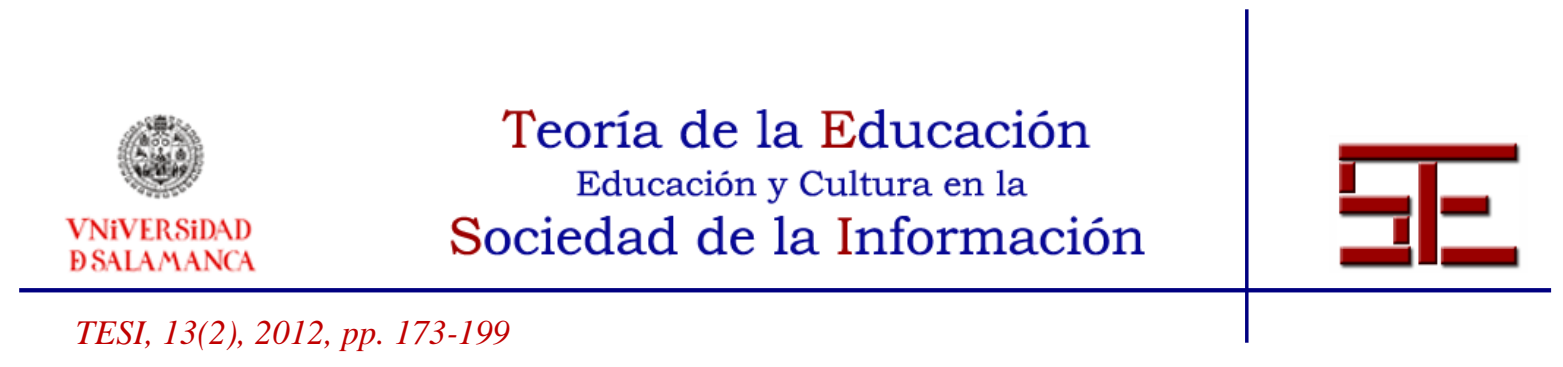

\title{
PERCEPTIONS OF THE FUTURE TEACHERS ABOUT THE ORGANIZATIONAL CULTURE OF THE SECONDARY EDUCATION PRACTICAL CENTRES
}

\begin{abstract}
The general objective of this study is to show the initial results of a questionnaire about organizational culture in secondary education centres answered for 57 future teachers who are students of the University Master's degree in compulsory Secondary Education and High School in the University of Malaga (Specialty Technology). The results show that the future teachers think that they should give class taking into account the diversity of students in their classroom, they should review their techniques and teaching strategies in the training process and their continuous updating. Besides, there are differences in the perception of the organizational culture of secondary education centres depending on the gender related to variables like the functions of the institution, government centres, funding, methodology, students, assessment and relations with the environment. The data are useful for go the improvement of training actions, let evaluate the slants and to adaptat to the challenges of the Secondary Education.
\end{abstract}

Keywords: Master's degree; Practicum; organizational culture; gender; secondary education.

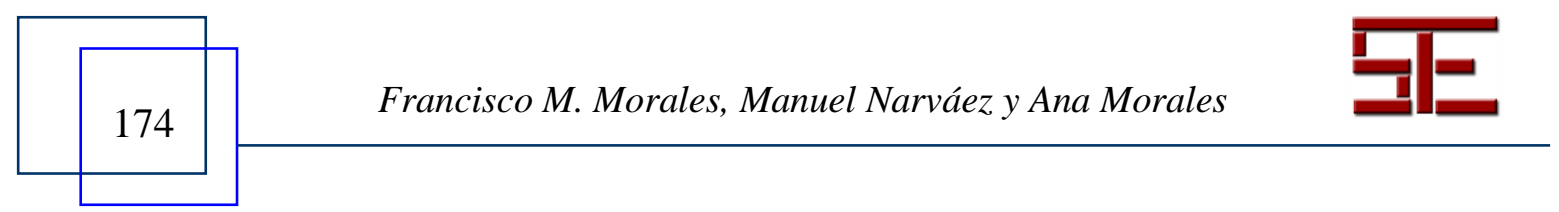




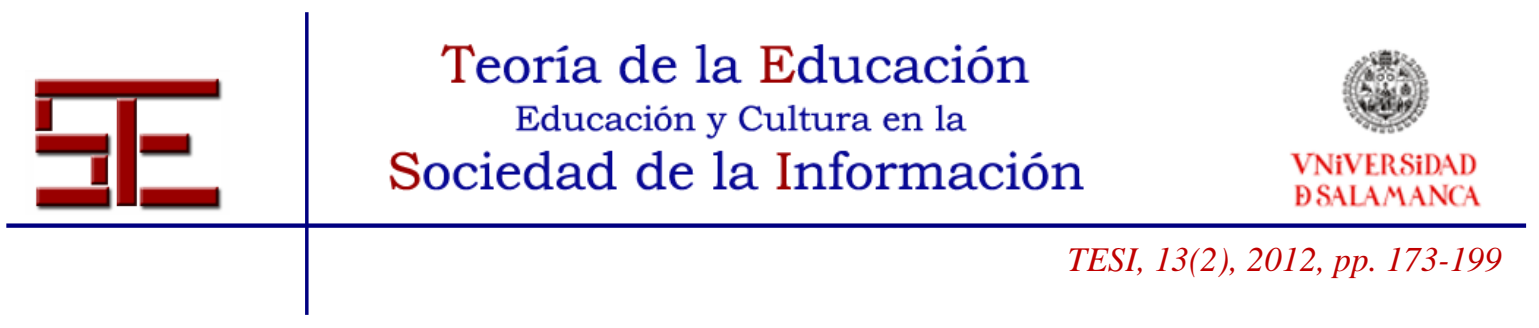

\section{PERCEPCIONES DE LOS FUTUROS DOCENTES SOBRE LA CULTURA ORGANIZACIONAL DE LOS CENTROS DE PRÁCTICAS EXTERNAS DE EDUCACIÓN SECUNDARIA}

Fecha de recepción: 29/01/2011; fecha de aceptación: 27/03/2012; fecha de publicación: 26/07/2012

Francisco Manuel Morales Rodríguez

framorrod@uma.es

Universidad de Málaga

Manuel Alejandro Narváez Peláez

mnarvaez@uma.es

Universidad de Málaga

Ana María Morales Rodríguez

anamoralesrcomunicacion@gmail.com

Universidad de Málaga

\section{1.- INTRODUCCIÓN}

En la sociedad del siglo XXI es la educación secundaria, de todos los sectores de la enseñanza, uno de los que más expansión ha experimentado y ha sido reconocida (aunque con diversos grados de percepción) como factor esencial para la plena realización personal, así como para el desarrollo y el progreso de las respectivas sociedades. Como plantean Marcelo (1987) y Otero-López, Castro, Villardefrancos y Santiago (2009) el plantearse cuál es la cultura organizacional en los IES nos lleva inevitablemente a reflexionar sobre los principios pedagógicos y educativos que comparte el equipo docente de cada centro. Y continúa poniendo de manifiesto cómo ello nos remite a la raíz de estos principios. ¿De dónde surgen los modelos pedagógicos de los que se vanagloria el profesorado? Buena parte de la literatura sobre el pensamiento del profesor según dicho autor evidencia la importancia que tienen los modelos ejercidos por nuestros profesores en el modelo que adoptamos como profesor. Ésta es la razón principal por la que nos hemos preguntado sobre la semejanza de ésta con la del futuro profesorado. Por todo lo anterior, nos hemos acercado a los estudiantes para ver cuán parecida es su forma de abordar la educación a la del profesorado que está ejerciendo su docencia en los centros de Educación Secundaria. Considerando la imitación de los modelos didácticos de los profesores de los cuales hemos sido alumnos $\mathrm{y}$, especialmente, en lo que se refiere a los modelos didácticos de los profesores que

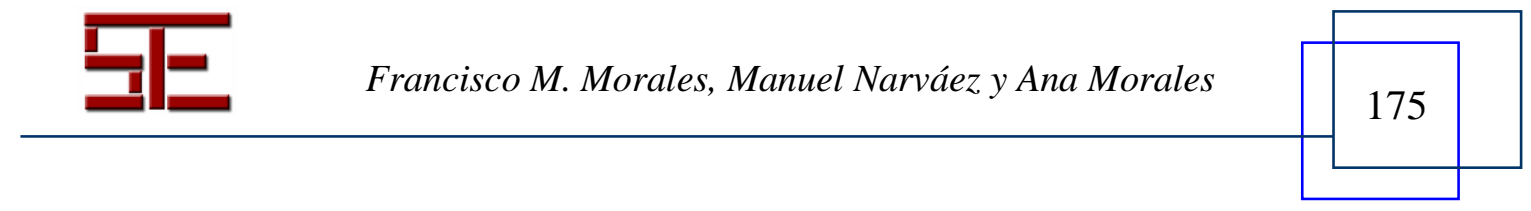




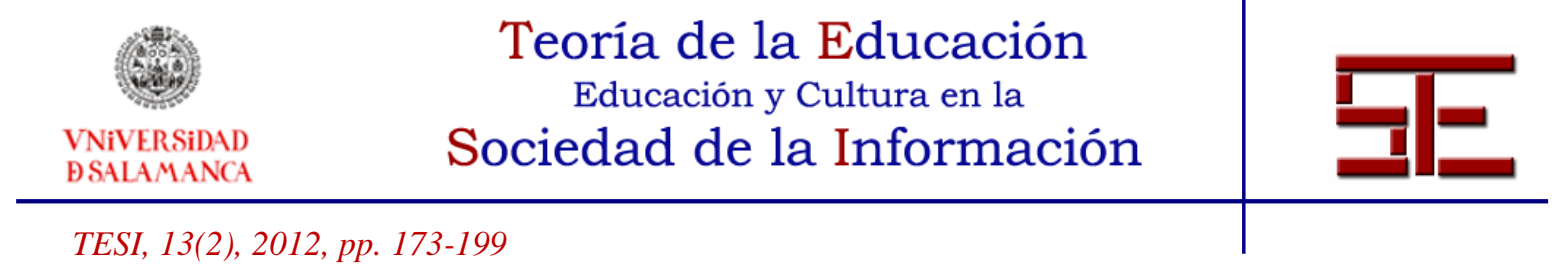

hemos admirado o que recordamos de manera especial. Por ello los estudiantes, sujetos a clases cuyo profesorado tiene una particular preparación y sensibilidad didáctica, pueden ser susceptibles de recibir e imitar modelos didácticos más acordes con las nuevas necesidades educativas de los adolescentes del siglo XXI. Por todo lo anterior, la cultura en lo referente a los valores educativos, a los modelos didácticos, a la concepción de la enseñanza/aprendizaje, al objetivo de la evaluación, etc., puede ser especialmente interesante por cuanto supone algo de propedéutico y, como mínimo, nos permite ver hasta qué punto influye en el profesorado la cultura existente en los centros o bien visualizar si esta cultura viene determinada por las creencias anteriores a la entrada al centro. Se viene planteando que no podemos tener excesiva tranquilidad respecto a la seguridad de que la cultura existente en los IES fuera la más necesaria para hacer frente a los auténticos retos y desafíos de la educación que tiene planteadas hoy la sociedad, por lo que habría la posibilidad de prever para los futuros docentes y, en consecuencia, discentes unos valores educativos más acordes con las nuevas necesidades educativas de los adolescentes del siglo XXI.

En estudios actuales (Otero-López et al., 2009) se viene destacando la importancia de la cultura compartida así como de las subculturas existentes en los IES para el buen desarrollo y funcionamiento del centro, así como para la consecución de los objetivos planificados. Además puede señalarse que los objetivos de los IES se han ido modificando en los últimos años, puesto que el sistema educativo ha experimentado continuos cambios, así como la evolución de nuestra sociedad, que requiere de una función más social y comprensiva y no sólo instructiva (Hernández y Sancho, 1989), lo que conlleva una transformación de la función profesional del docente. Como señala Rivas (2003: 4) cuando hablamos de cultura es indispensable atender a los procesos políticos y sociales que tienen lugar en el interior de los centros educativos, lo que implica también estar atentos a los significados que generan las acciones que tienen lugar en la institución que se quiere estudiar. Los diferentes estudios teóricos coinciden en que existen dos perspectivas que han influido en el concepto de cultura organizacional: la que observa directamente el comportamiento, lenguaje y uso de los objetos materiales en los miembros de la institución; y una segunda, que es la que se refiere a las ideas, valores y creencias que los miembros pueden tener en común. En los tiempos que nos toca vivir resulta obvio que la institución escolar posee una cultura organizacional susceptible de ser evaluada. Para comprender la complejidad de los términos que aquí se tratan será importante definir qué se entiende por cultura: "La cultura lo impregna todo, es creación del significado sobre lo que vemos, sobre lo que queremos y deseamos. Influye en las relaciones sociales: formas de percibir al otro,

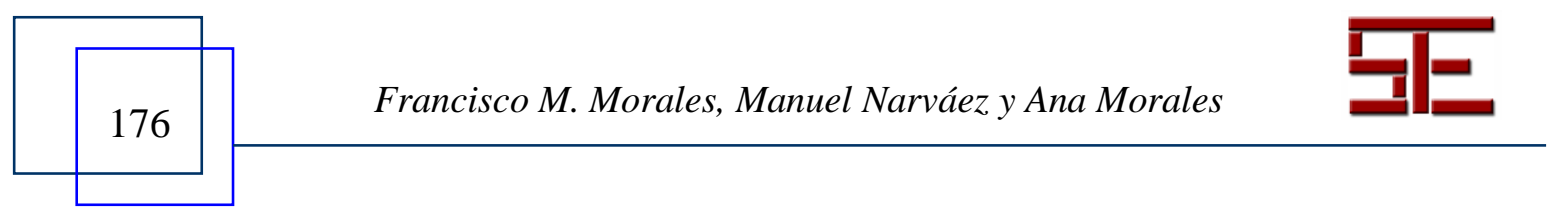




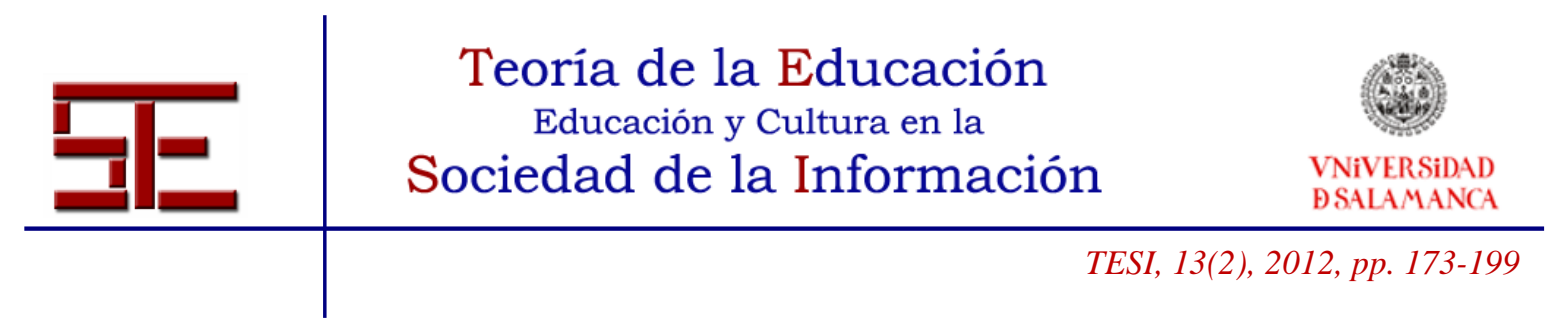

cómo lo interpretamos, actuamos delante de él y con él, cómo nos comunicamos, reaccionamos, etc. Actuamos de acuerdo a unos determinados significados. Por cultura entendemos las formas de vida, y la cultura social constituye una parte importante de ésta” (Martín, 2003).

La cultura puede ser un factor de enfrentamiento o consenso. Por ello, se hace necesario conocerla y analizarla para comprender los procesos de cambio que se producen en el interior de las organizaciones sociales. La cultura es también dinámica y viva, es el producto de diferentes visiones que tienen los miembros en el interior de la institución; por lo que es importante que las investigaciones desarrolladas en relación a este ámbito se enfoquen y se diseñen para contextos específicos. Así, en el momento de abordar esta clase de estudios, no se puede olvidar que la cultura está inmersa en procesos de cambios constantes y que, por consiguiente, será diferente en cada centro de enseñanza.

La cultura existente en las instituciones no siempre es aceptada, asimilada, compartida y reconocida por la totalidad de los miembros que conforman una organización. Resulta evidente que cada centro es una realidad única e irrepetible, por eso es por lo que "hablar de cultura organizacional es reconocer que en el sí de cada centro existe una estructura organizativa, formas de interrelación, prácticas de actuación y sistemas de creencias, tradiciones, valores y símbolos que conforman una manera de hacer, una realidad de significados peculiares e idiosincrásicos" (Gairín, 2003: 230). Este autor establece, entre otras, las siguientes funciones de la cultura organizacional:

- Fundamenta el clima y cataliza la comunicación.

- Transmite un sentido de identidad a sus miembros.

- Define los límites de la organización; establece, por lo tanto, la distinción entre un centro escolar y los otros.

- Facilita la creación de un compromiso personal como algo más amplio que meros intereses particulares y a menudo egoístas del individuo.

- Ayuda a incrementar la continuidad del sistema social.

- Es fundamental precisar que dentro de una organización no sólo existe una cultura, sino que también hay subculturas que son compartidas por sus miembros.

Puede señalarse que las acciones que se producen y comparten en el transcurso de la interacción entre los sujetos generan un discurso que se puede denominar cultura y que dicha cultura se "concreta, se mantiene y se transmite a través de símbolos y prácticas o,

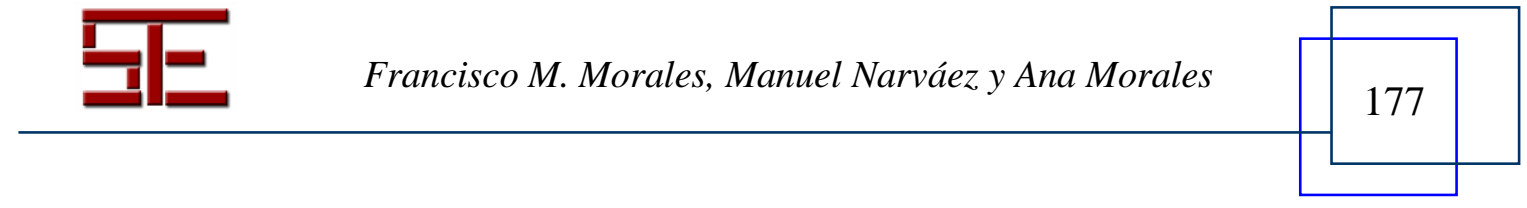




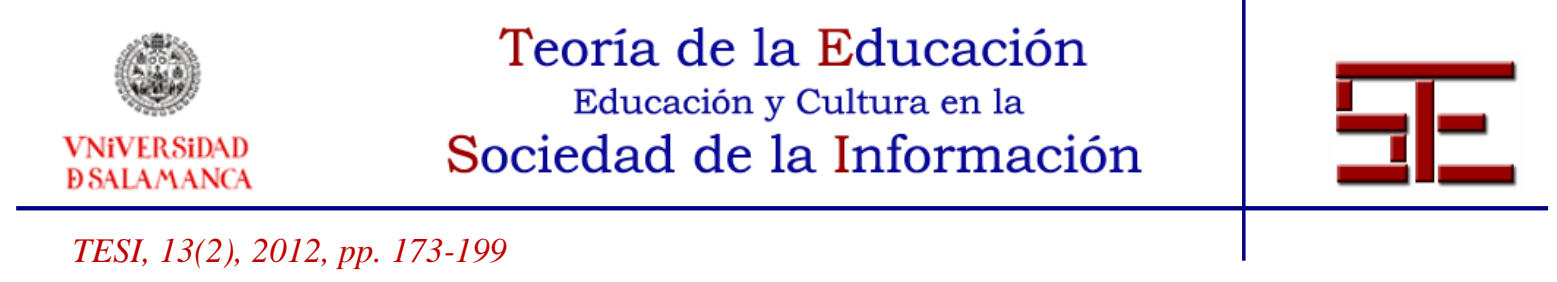

de forma más precisa, a través del significado que estos símbolos y actuaciones contienen" (Armengol, 2001: 24).

Para Armengol (2001: 32), la cultura organizacional escolar se puede definir como: "Conjunto de normas, creencias y valores compartidos que constituyen el marco interpretativo de referencia e identidad (símbolos y significados) del centro; son aprendidos y/o compartidos por el grupo".

Existen varias definiciones del significado de cultura organizacional, pero los expertos coinciden en que este tipo de cultura nace de las personas que forman la institución y de las prácticas que éstas realizan en su interior.

Entre las características propias de la cultura organizativa pueden destacarse según Armengol (2001: 33) las siguientes:

- La cultura posee una doble cara, puesto que puede aglutinar o separar a los miembros de una institución.

- Las instituciones educativas crean su cultura desde el interior con la cultura que poseen los profesores y las visiones de los alumnos. Y también desde el exterior con el espacio cultural que ocupa la comunidad escolar y las intervenciones del sistema educacional.

- Es indudable que cada centro y aula generan y poseen su propia cultura.

- Dentro del centro educativo existe una cultura dominante, pero también conviven diferentes subculturas.

- La cultura proporciona un marco para el desarrollo y la adaptación del sistema escolar; que es el espacio para el intercambio de significados; y que genera unas actitudes que impulsan o inhiben el comportamiento de los miembros de una determinada institución.

El presente estudio se centra en la percepción de la cultura organizativa de los centros de secundaria por parte de futuros docentes pertenecientes al reciente Máster Universitario en Profesorado de Educación Secundaria Obligatoria y Bachillerato, Formación Profesional y Enseñanza de Idiomas por la Universidad de Málaga. Por ejemplo, como señalan estudios como los de Guil y Mestre (1998: 239), es necesario analizar la tendencia del profesorado a relacionarse y construir culturas ligadas a sus departamentos, y lo complejo que es configurar una verdadera cultura compartida de centro que oriente y afiance el funcionamiento educativo de todo el instituto.

Se hace relevante conocer, explicar e identificar los procesos que derivan de una

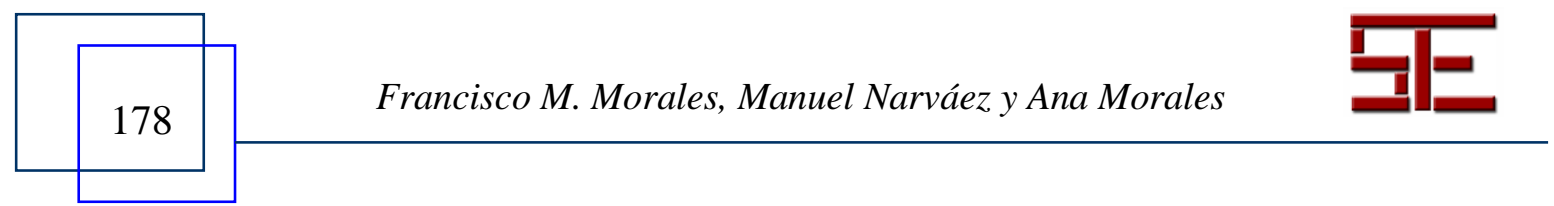




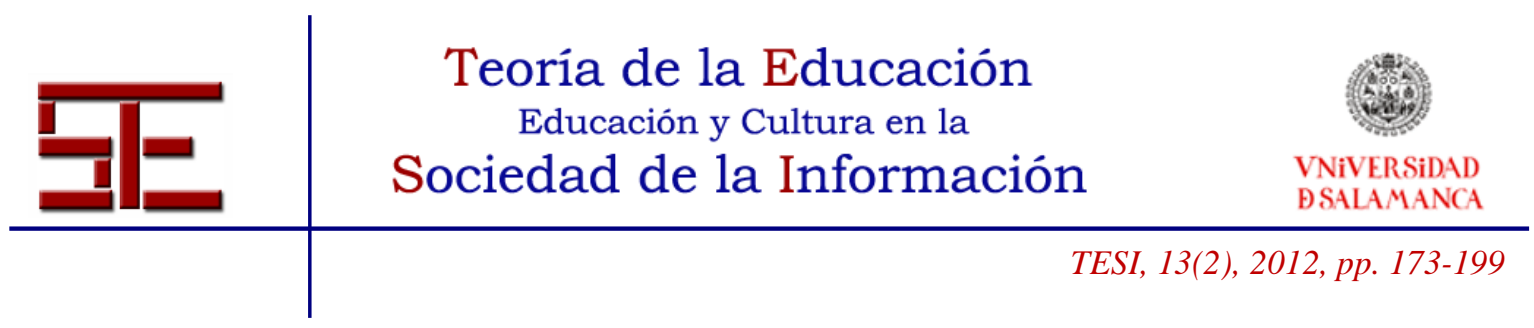

determinada cultura organizacional, así como identificar la percepción de la cultura organizacional existente en un centro educativo con objeto de contribuir al fomento de las relaciones interpersonales en el interior de la institución y, por tanto, su compromiso con las funciones que se deben desarrollar.

En este sentido en estudios como los de Rivera (2000) se concluye que el conocimiento de la cultura organizacional en el interior de la Escuela conducirá hacia una educación de calidad: "La congruencia en los objetivos de la escuela, especialmente, respeto a la calidad de los procesos de enseñanza/aprendizaje, el rol del director como líder que usa la simbología asociada con la cultura organizacional de la escuela, las expectativas de rendimiento de los profesores y alumnos, las relaciones positivas tanto internas como externas del centro, son algunas de las características de un establecimiento de la cultura organizacional propicia para un servicio educativo de calidad". Asimismo, como se considera desde los nuevos aires europeos, la mayor eficacia y eficiencia educativa viene asociándose cada vez más a la existencia de una cultura participativa, cooperativa y colaborativa, con una mayor colaboración entre los integrantes de un centro que deje de lado el individualismo, que es sin duda uno de los mayores problemas que afrontan los centros educativos y que revierta, sin lugar a dudas, en beneficio de una mayor calidad educativa.

\section{2.- MÉTODO}

\section{1.- Participantes}

Los participantes han sido 57 futuros docentes estudiantes del Máster Universitario en Profesorado de Educación Secundaria Obligatoria y Bachillerato, Formación Profesional y Enseñanza de Idiomas por la Universidad de Málaga correspondientes a la especialidad de Tecnología, Informática y Procesos Industriales, con edades comprendidas entre los 22 y 49 años, que actualmente realizan el Prácticum del Máster Universitario en Profesorado de Educación Secundaria Obligatoria y Bachillerato, Formación Profesional y Enseñanza de Idiomas de la Facultad de Ciencias de la Educación de la Universidad de Málaga. El 71,93 \% de la muestra son hombres y el $28,07 \%$ son mujeres. Todos respondieron al cuestionario en una aplicación colectiva en clase.

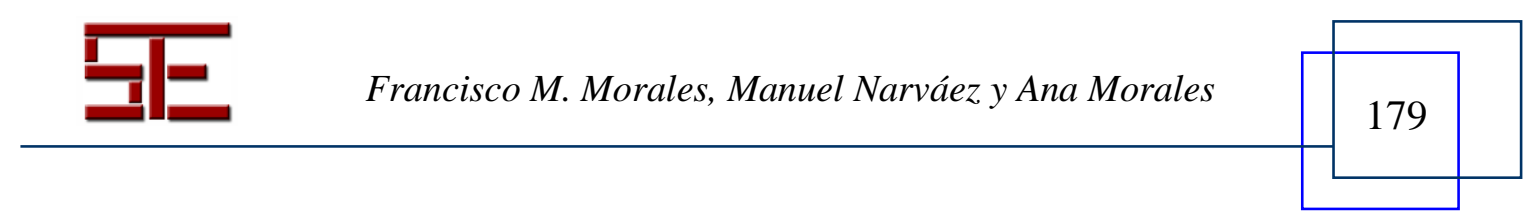




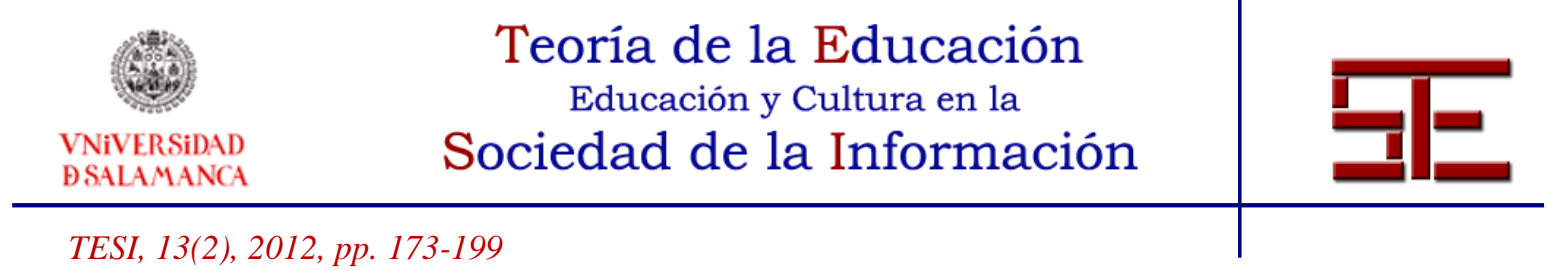

\section{2.- Instrumentos}

Cuestionario sobre Cultura Organizacional en los Centros de Educación Secundaria. El cuestionario está formado por 77 ítems cerrados con formato de respuesta tipo Likert de 1 a 5 para que contesten en qué grado están de acuerdo con una serie de afirmaciones, siendo 1 el menor grado de acuerdo y 5 el mayor grado de acuerdo. Los 10 aspectos o manifestaciones a las que hacen referencia dichos ítems son los siguientes: funciones de la institución, gobierno de los centros, financiación de los centros, investigación, perfil del profesorado, metodología, alumnado, evaluación, Tecnologías de la Información y de la Comunicación (TIC) y relaciones con el entorno. Se trata de un cuestionario que se viene empleando en estudios consolidados (Armengol, 2001; Tomás, Mas y Jofre, 2006) para identificar la cultura organizativa en los Centros de Educación Secundaria.

\section{3.- Procedimiento}

Los participantes han realizado el cuestionario de forma voluntaria. Sus datos han sido introducidos en el SPSS para su posterior análisis. Se llevó a cabo la administración del instrumento de evaluación a los participantes de forma colectiva en hora de clase, según fecha y hora determinada por el calendario académico de la Universidad. La administración del cuestionario fue llevada a cabo por psicólogos expertos en el campo.

\section{4.- Análisis de datos}

La codificación y análisis de datos se hizo con el paquete estadístico SPSS 15.0. Además de realizar análisis descriptivos reflejándose porcentajes, medias y desviaciones típicas, se realizó la prueba $\mathrm{T}$ de Student para muestras independientes para ver si existen diferencias estadísticamente significativas en función del género. Dada la cantidad de información que se desprende de los resultados obtenidos sólo se comentan aquellos datos más relevantes o en los que existen diferencias estadísticamente significativas.

\section{3.- RESULTADOS}

Los resultados respecto al cuestionario sobre cultura organizacional en los centros de Educación Secundaria se presentan en las Tablas 1 a 10. Podemos ver, que la mayoría de los encuestados muestra estar muy de acuerdo con los aspectos reflejados en los ítems referidos a si "El profesor tiene que priorizar su capacitación en la actualización de técnicas y estrategias didácticas de enseñanza/aprendizaje"; "Es preciso

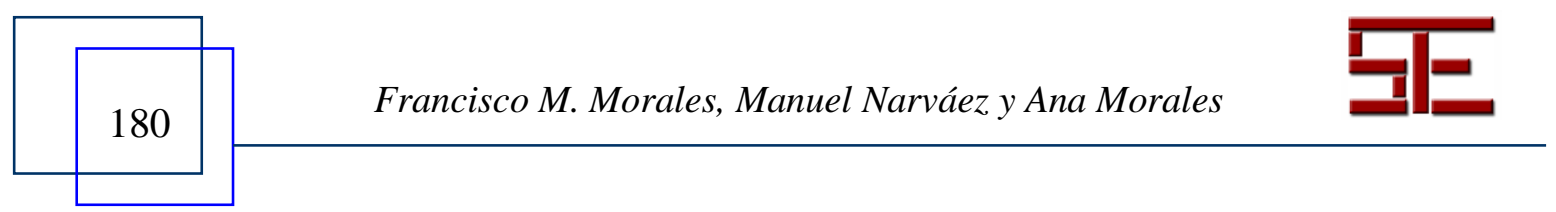




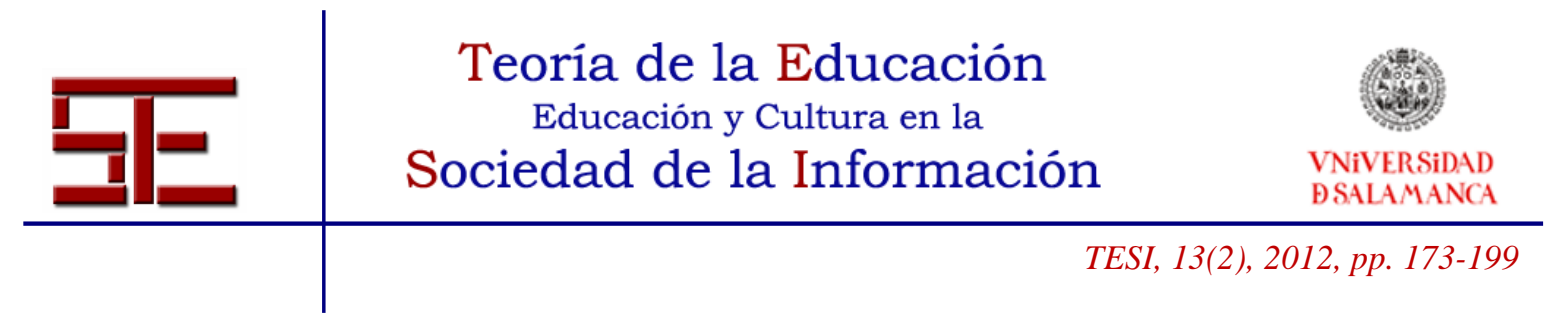

promover canales efectivos de participación del alumnado en la vida del centro"; "El alumnado tiene que encontrar en el contexto escolar un espacio privilegiado para el aprendizaje, la formación y la convivencia que contribuya a su formación como ciudadano y ciudadana"; "La Escuela no es el único lugar donde se produce el aprendizaje y la formación del alumnado, y por ello la labor educativa de la Escuela se ha de vertebrar con el conjunto de la comunidad local" (puntuación media $=4.0 ; 3.9$; 4.0 y 4.7 respectivamente). Con respecto a los ítems en los que se han obtenido las puntuaciones medias inferiores, éstos hacen referencia al hecho de que "La función más importante del profesor es la transmisión del contenido de la materia..."; "La financiación de los centros permite disponer de recursos económicos para garantizar una educación de calidad"; "El proceso de enseñanza/aprendizaje tiene que basarse principalmente en la clase magistral" (puntuación media $=2.3,2.3$ y 1.8 respectivamente).

A continuación en las Tablas 1 a 10 se muestran las medias y desviaciones típicas (DT) obtenidas por los futuros docentes del Máster de Educación Secundaria Obligatoria y Bachillerato, Formación Profesional y Enseñanza de Idiomas por la Universidad de Málaga correspondientes a la especialidad de Tecnología, Informática y Procesos Industriales en cada uno de los aspectos evaluados.

Tabla 1. Funciones de la institución

Ítem

1. La finalidad de los IES es instructiva y se priorizan las ayudas que se le ofrecen para mejorarla
Media (DT) en muestra total futuros docentes Máster Secundaria

$3.6(.91)$ aspectos relacionados con la Educación en Valores

3. La finalidad de los IES es de custodia y se priorizan mecanismos organizativos y administrativos para llevarla a término

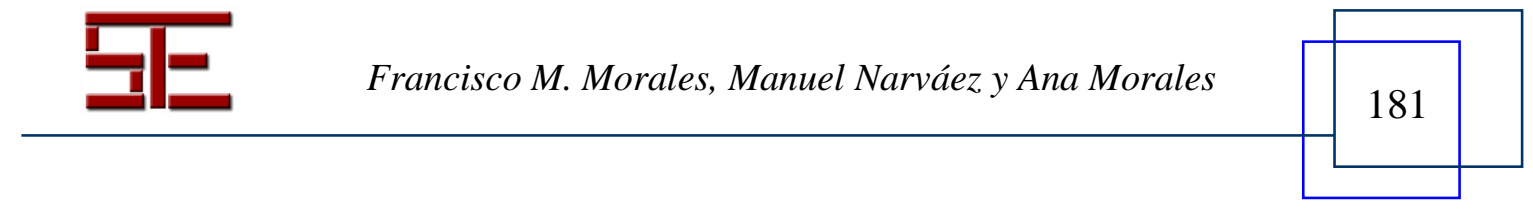


4. La finalidad de los IES es de custodia y se priorizan mecanismos organizativos y administrativos para llevarla a término

5. La calidad de la Educación Secundaria está relacionada con la cantidad de contenidos aprendidos por el alumnado

6. Los centros de Secundaria establecen redes de trabajo compartido con el resto de entidades e instituciones de su entorno y han de ser un dinamizador cultural del territorio

7. Los IES se relacionan con el entorno a través del trabajo individual de algunos profesores

8. Los IES se relacionan con el entorno a partir del desarrollo de proyectos institucionales que implican a todo el profesorado

9. Se consideran las necesidades educativas, tecnológicas y culturales de la sociedad en el momento de realizar la planificación docente

Tabla 2. El gobierno de los centros

Ítem

1. El sistema de acceso y elección del equipo directivo permite garantizar el funcionamiento democrático del centro

2. El Consejo Escolar representa a la comunidad educativa y tiene un papel decisivo en la gestión del centro

3. Los órganos unipersonales de gobierno son absolutamente necesarios

4. La elección de los cargos de gestión y dirección se realiza prioritariamente entre el profesorado más capacitado para hacerlo
Media (DT) en muestra total futuros docentes Máster Secundaria

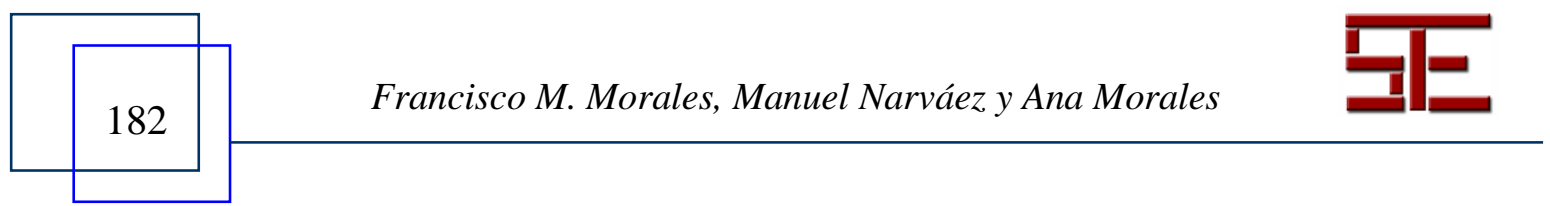




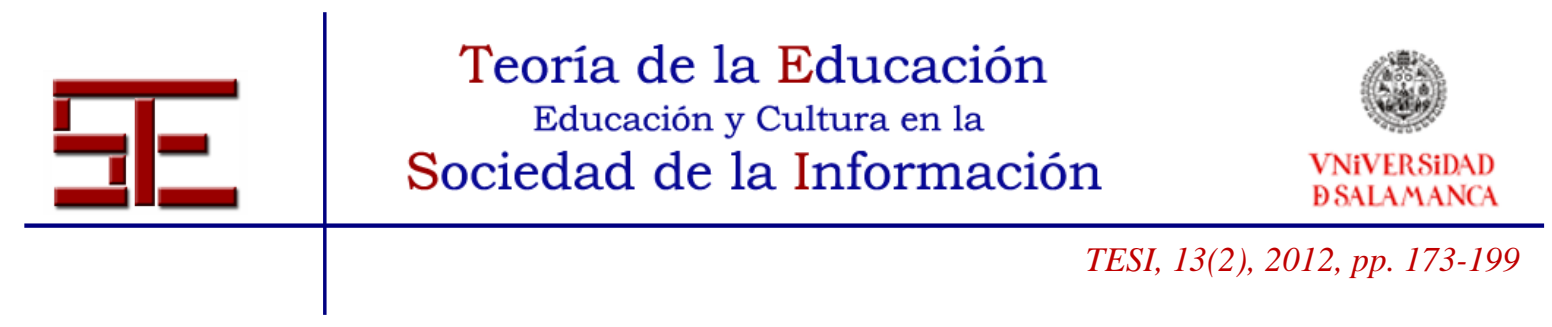

5. El número de miembros que componen los órganos colegiados

$3.1(1.05)$ (claustro, departamento, consejo escolar...) permite un funcionamiento ágil

6. Las decisiones de los órganos colegiados tienen un consenso y una participación muy amplios

7. El funcionamiento de estos órganos se justifica porque garantiza la transparencia, participación e implicación de todos

8. Los centros de Secundaria tienen un grado suficiente de autonomía en todos los ámbitos para garantizar un servicio de calidad

9. Los centros de Secundaria están sometidos a una serie de condicionantes legales y contextuales que impiden funcionar con una autonomía real

10. La autonomía es una condición absolutamente necesaria para dar un servicio de calidad a la sociedad

Tabla 3. La financiación de los centros públicos de Secundaria

Ítem

1. La financiación de los IES proviene exclusivamente de fondos públicos

2. Los IES buscan recursos financieros complementarios en entidades privadas (empresas, fundaciones, etc.)

3. Los IES establecen contratos con la Administración educativa sobre el uso de sus fondos y recursos y la financiación tendría que estar sometida al cumplimiento del contrato

4. La asignación del presupuesto a los IES está sometida a sus necesidades reales con independencia de los criterios generales establecidos por el conjunto del sistema
Media (DT) en muestra total futuros

docentes Máster Secundaria

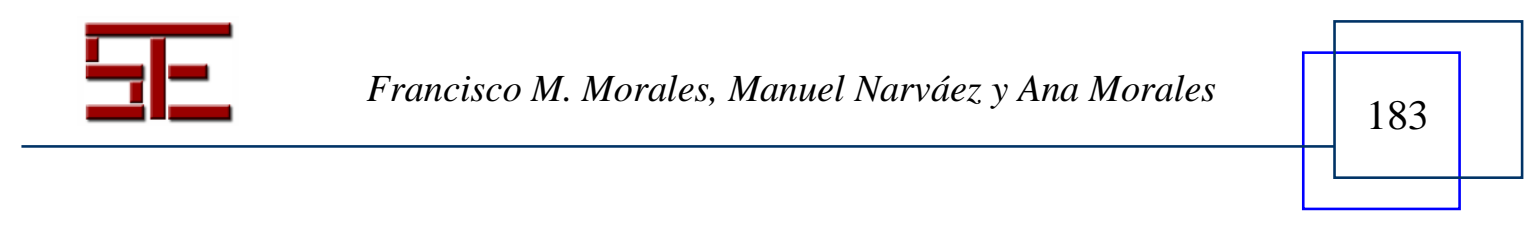




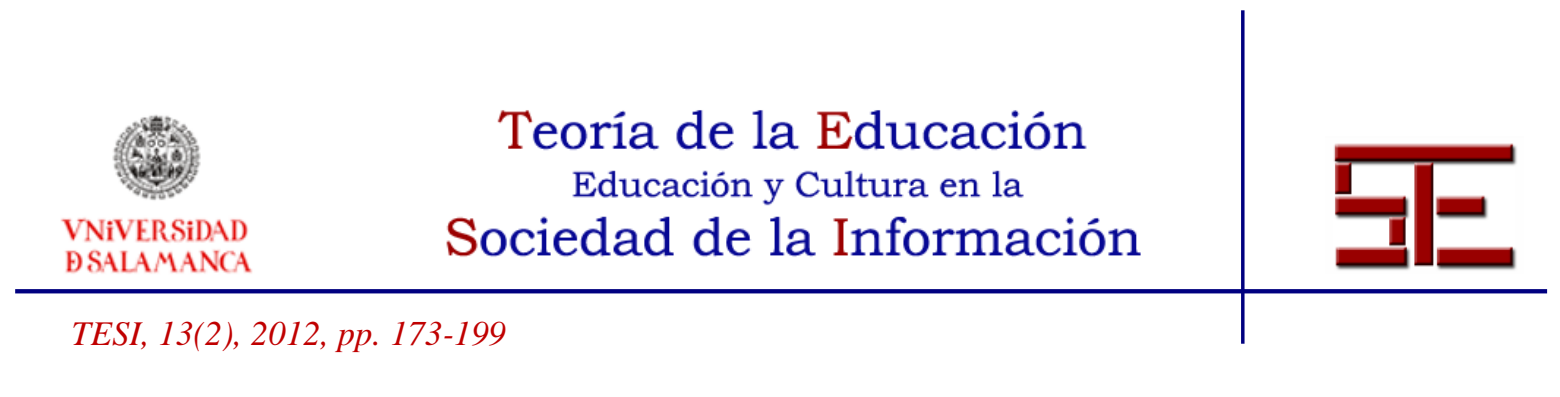

5. Las becas y ayudas que reciben los estudiantes satisfacen todos los gastos que les supone cursar la Educación Secundaria

6. La financiación de los centros permite disponer de recursos económicos para garantizar una educación de calidad

Tabla 4. La investigación

\begin{tabular}{|c|c|}
\hline Ítem & $\begin{array}{l}\text { Media (DT) en muestra total } \\
\text { futuros docentes Máster } \\
\text { Secundaria }\end{array}$ \\
\hline $\begin{array}{l}\text { 1. La investigación es una función a desarrollar dentro del } \\
\text { centro de Secundaria }\end{array}$ & 3.7 (1.17) \\
\hline $\begin{array}{l}\text { 2. Los centros de Secundaria reciben recursos para } \\
\text { desarrollar proyectos de investigación }\end{array}$ & $2.5(1.06)$ \\
\hline $\begin{array}{l}\text { 3. Se divulgan los resultados de las investigaciones } \\
\text { realizadas en los centros educativos (licencias de estudio, } \\
\text { equipos de trabajo, etc.) de la misma forma que se } \\
\text { divulgan otras investigaciones }\end{array}$ & $2.4(.99)$ \\
\hline $\begin{array}{l}\text { 4. La administración educativa establece las temáticas } \\
\text { prioritarias sobre las que los centros de Secundaria } \\
\text { tendrían que hacer investigación }\end{array}$ & $2.8(.80)$ \\
\hline
\end{tabular}

Tabla 5. El perfil del profesorado

\begin{tabular}{lc}
\hline Ítem & $\begin{array}{c}\text { Media (DT) en muestra total futuros } \\
\text { docentes Máster Secundaria }\end{array}$ \\
1. La función más importante del profesor es la transmisión \\
del contenido de la materia. El profesor tiene que ser un \\
académico, intelectual que procure que los alumnos \\
extraigan el máximo de información de su asignatura
\end{tabular}

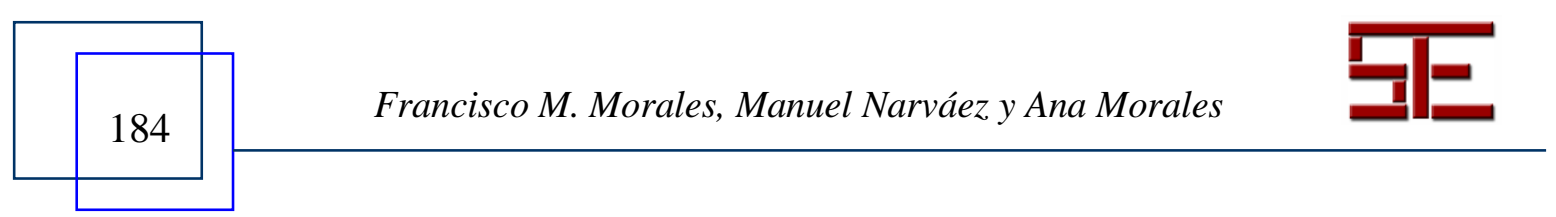




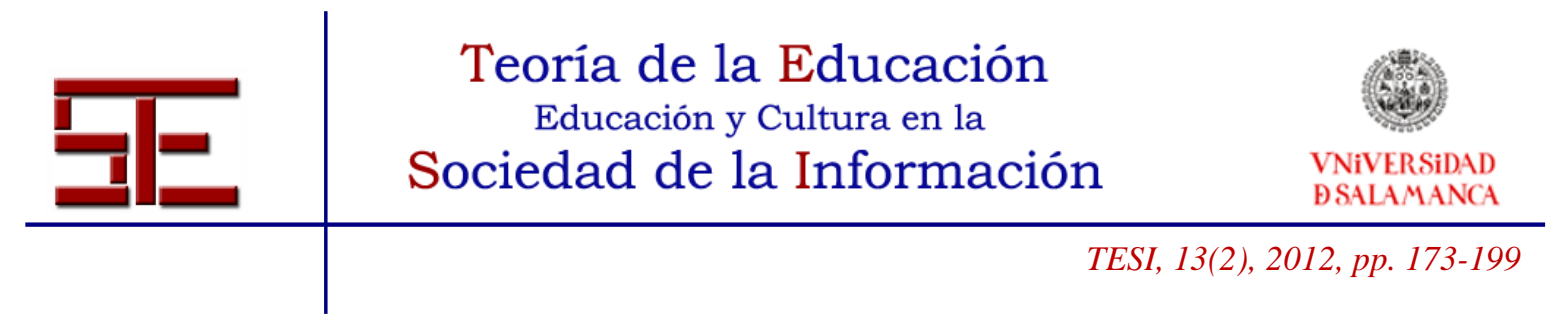

para disponer de ella cuando sea necesario

2. La función del profesorado es la de facilitar los aprendizajes de los alumnos, destacando por su capacidad de reflexión, opina que una buena práctica profesional depende menos del conocimiento objetivo o de modelos rigurosos que de la capacidad de reflexionar antes de tomar una decisión, y esto es lo que intentaría transmitir a sus alumnos

3. El profesorado constituye la transformación de la sociedad, construyendo y seleccionando el contenido cultural a partir de la reflexión crítica y de las experiencias de aprendizaje vividas por el alumnado. Esto permite un dominio sobre la asignatura y abrir posibilidades de cambio

4. El profesorado promueve el rigor científico y académico en el tratamiento del temario de la asignatura

5. El profesor cree que lo más importante son los alumnos $\mathrm{y}$, por tanto, procura centrar el currículum de la asignatura en sus intereses y capacidades de acuerdo con la realidad del momento. El profesor selecciona, por tanto, los contenidos a partir del debate y la negociación entre él y los alumnos

6. El conocimiento de la materia se construye con las aportaciones de las nuevas generaciones. El profesor mantendría en interrogación constante su propia actividad y los propios protagonistas para ofrecer un contenido que forme a los alumnos a resolver los problemas de su tiempo

7. Todos los alumnos tendrían que llegar a dominar los mismos contenidos básicos del currículum. Por esto, el profesor transmite unidireccionalmente los contenidos de su asignatura

El objetivo de la docencia sería la autorrealización del alumno, no la acumulación de contenidos. La formación cultural del alumno es tanto o más importante que la especialización en un área de conocimiento

9. El profesorado se preocupa para formar individualmente a los alumnos con razonamiento crítico, y para ser

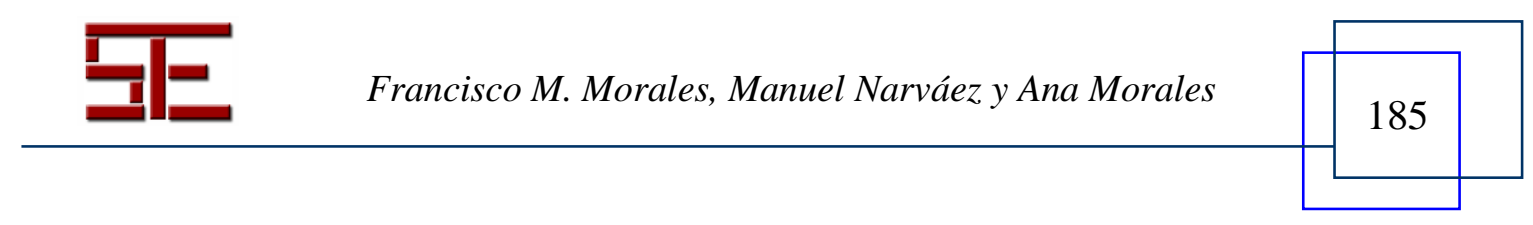




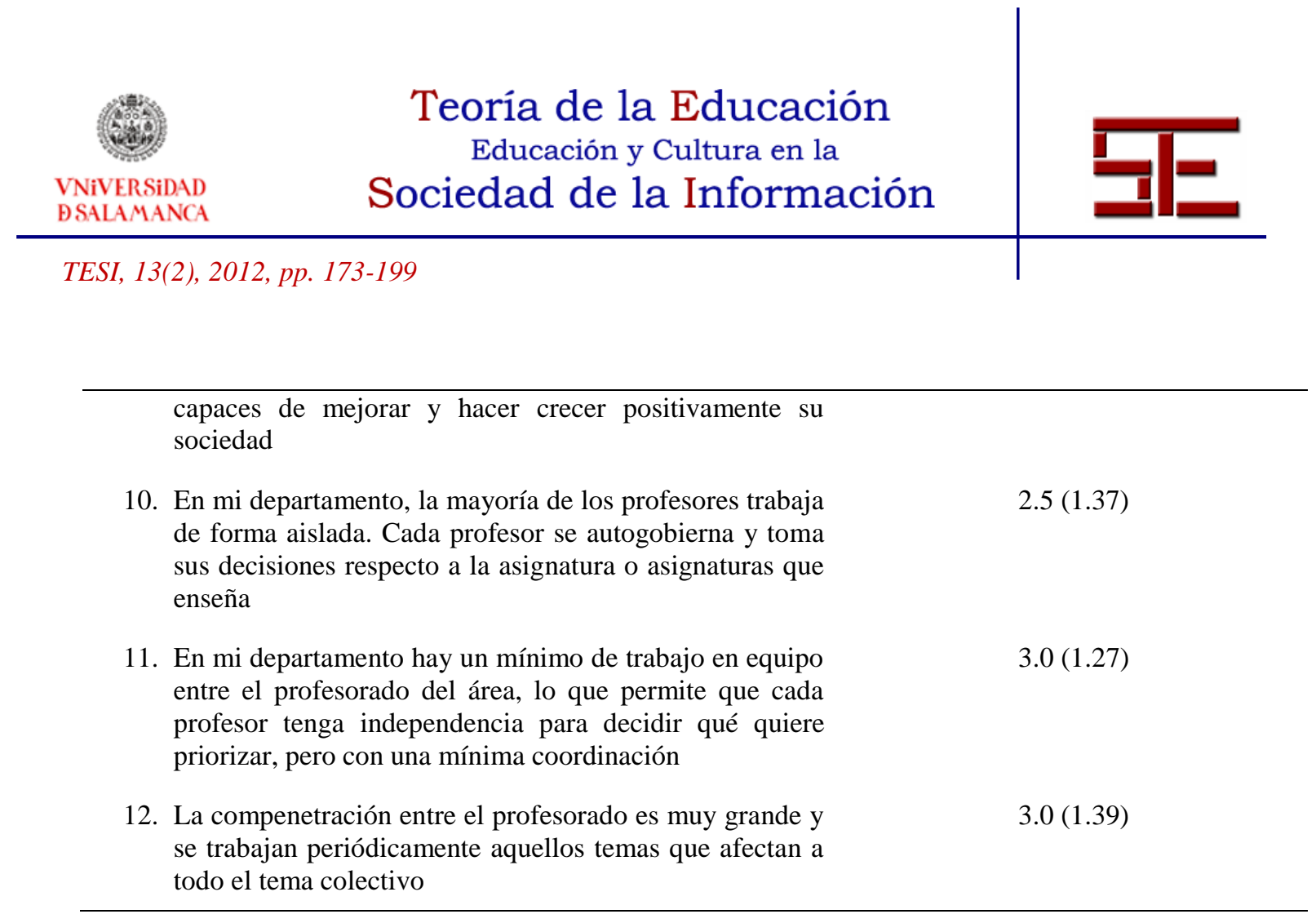

Tabla 6. La metodología

Ítem

1. El proceso de enseñanza/aprendizaje tiene que basarse principalmente en la clase magistral

2. El proceso de enseñanza/aprendizaje tiene que basarse principalmente en el debate y el desarrollo del espíritu crítico

3. El proceso de enseñanza/aprendizaje tiene que basarse principalmente en la búsqueda de información por parte del estudiante

4. El proceso de enseñanza/aprendizaje tiene que basarse principalmente en la realización de proyectos

5. El profesor tiene que priorizar su capacitación en la actualización de conocimientos para conseguir un dominio amplio de la materia

6. El profesor tiene que priorizar su capacitación en la actualización de técnicas y estrategias didácticas de
Media (DT) en muestra total

futuros docentes Máster

Secundaria

$1.8(.70)$

$3.7(.90)$

$4.0(.63)$

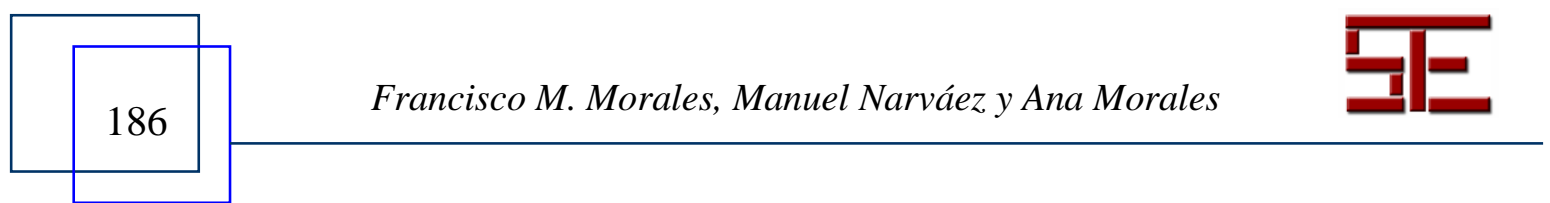




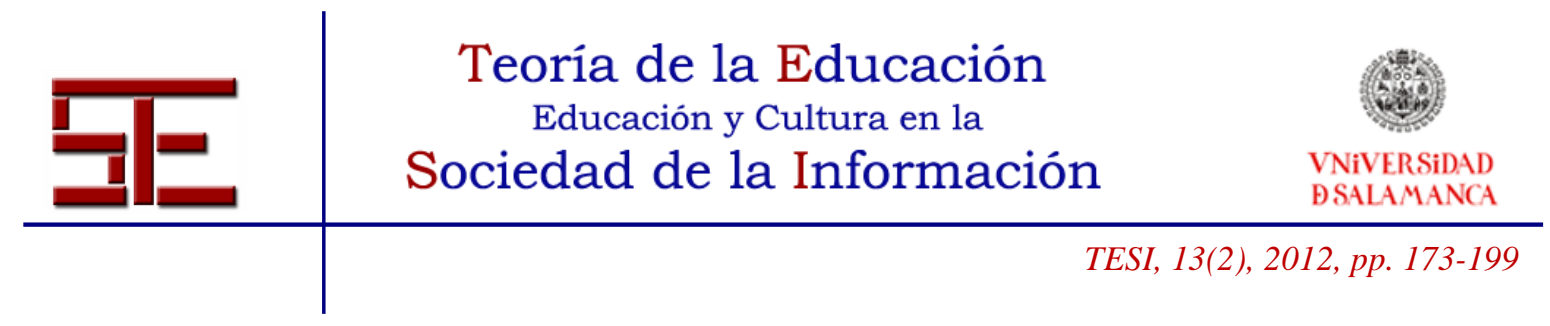

enseñanza/aprendizaje

7. El profesor tiene que priorizar su capacitación con la incorporación de estrategias y dinámicas de trabajo en grupo

8. Los aprendizajes tienen que evaluarse preferentemente a través de pruebas escritas sobre los contenidos de la asignatura

9. Los aprendizajes tienen que evaluarse preferentemente a través de actividades prácticas sobre los contenidos de la asignatura

10. Los aprendizajes tienen que evaluarse preferentemente a través de trabajos e informes sobre los contenidos de la asignatura

11. Los aprendizajes tienen que evaluarse preferentemente a través de dispositivos de auto-evaluación razonada y negociada sobre los propios aprendizajes

Tabla 7. El alumnado

Ítem

1. El bagaje sociocultural del alumnado y la propia evolución de la sociedad hacen necesaria la adaptación de la docencia a nuevas formas de aprendizaje

2. El sistema educativo es demasiado comprensivo y poco selectivo, hecho que dificulta una formación académica de calidad

3. El alumnado actual domina nuevas formas de comunicación y procesamiento de aprendizajes

4. Es preciso promover canales efectivos de participación del alumnado en la vida del centro

5. El alumnado recibe en el instituto formación de los expertos en las diferentes materias

6. El alumnado recibe en el instituto formación de los expertos en las
Media (DT) en muestra total futuros

docentes Máster Secundaria

$4.3(.68)$

$3.1(1.07)$

$3.0(1.13)$

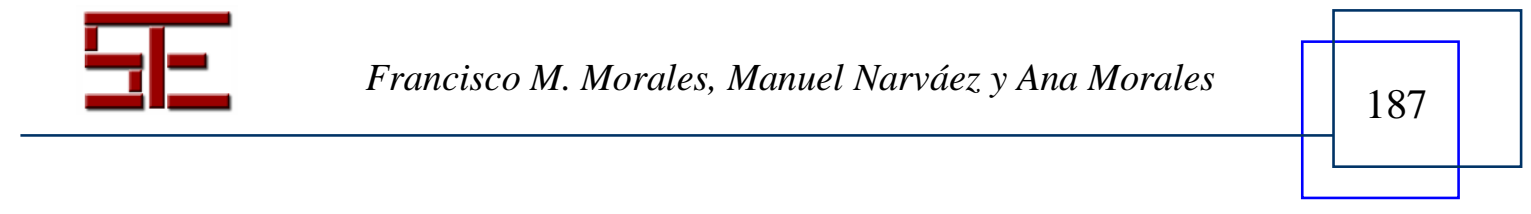


7. El alumnado y el profesorado son co-responsables del proceso de aprendizaje

$4.1(1.09)$

$3.9(.73)$ profesorado es su facilitador (tendría que poner en contacto al alumnado con las fuentes del conocimiento)

9. El alumnado está normalmente poco motivado y esto se traduce en poca participación en la clases y en conductas disruptivas

10. El alumnado tiene que encontrar en el contexto escolar un espacio privilegiado para el aprendizaje, la formación y la convivencia que contribuya a su formación como ciudadano y ciudadana

Tabla 8. La evaluación
Ítem

1. La evaluación del funcionamiento del centro es una tarea que permite mejorar su funcionamiento

2. El profesorado participa activamente en la evaluación interna del centro

3. El profesorado participa activamente en la evaluación externa del centro

4. La práctica docente incluye procesos de auto-evaluación

5. La auto-evaluación del profesorado tiene repercusiones en la mejora de la docencia
Media (DT) en muestra total futuros

docentes Máster Secundaria
$4.2(1.08)$

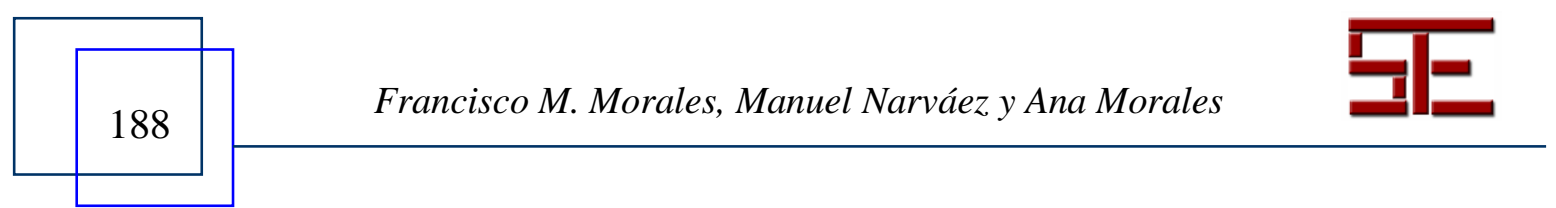




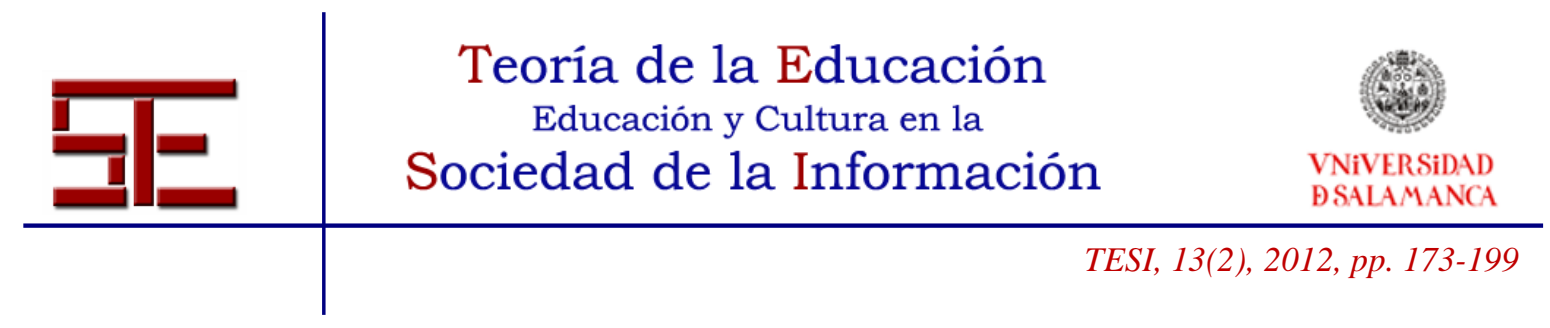

Tabla 9. Tecnologías de la Información y la Comunicación

Ítem

1. En las tareas de gestión del centro, se aprovechan adecuadamente las funcionalidades que proporcionan las TIC

2. En el centro se hace servir como herramienta de comunicación Intranet

3. En las tareas de docencia el profesorado utiliza las TIC

4. Las aulas de informática del centro están adecuadas para la docencia

5. La infraestructura de las TIC en las aulas (ordenador, cañón proyector, conexión a Internet, TV...) es suficiente.
Media (DT) en muestra total futuros

docentes Máster Secundaria

Tabla 10. Relaciones con el entorno

$$
\text { Ítem }
$$

1. La relación de los centros educativos con las instituciones/empresas a través de convenios de colaboración se ve como una fórmula interesante que acerca la educación a la sociedad

2. Ofrecer espacios y recursos del centro a la comunidad local y aprovechar espacios y recursos existentes en el entorno se ve como una fórmula interesante que beneficia a la acción educativa

3. Promover la participación del alumnado en actividades del entorno (asociaciones, voluntariado, actividades culturales, etc) se ve como una fórmula interesante de mayor integración y compromiso social del alumnado que se ha de fomentar desde la Escuela 


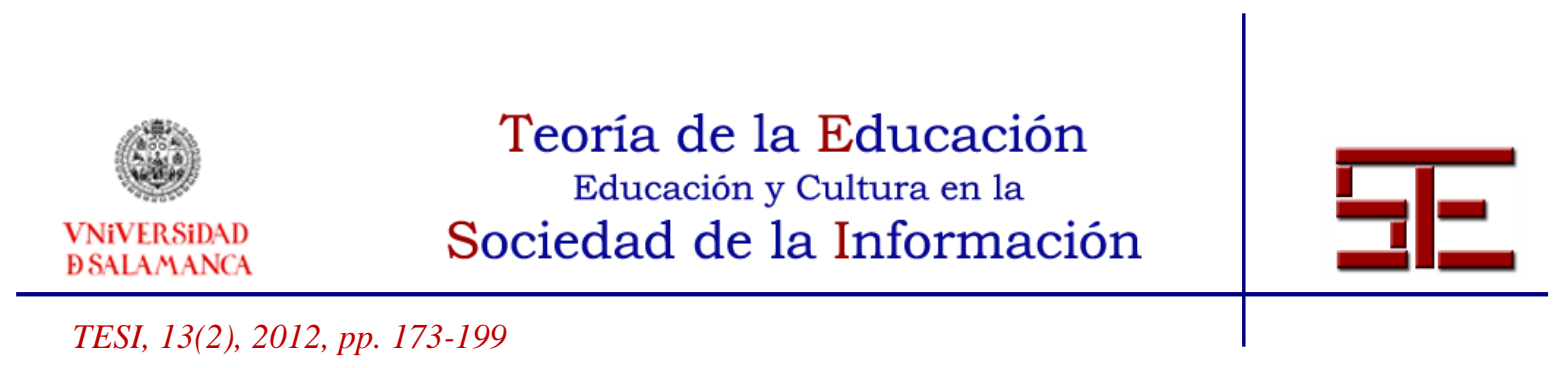

4. Facilitar el intercambio de experiencias entre el centro y su $4.4(.62)$ entorno enriquece y beneficia la labor educativa

5. La Escuela no es el único lugar donde se produce el aprendizaje y la formación del alumnado, y por ello la labor educativa de la Escuela se ha de vertebrar con el conjunto de la comunidad local

Como puede observarse, en términos generales, las puntuaciones medias obtenidas por los futuros docentes en muchas de las cuestiones planteadas son altas (escala de 1-5, 1 totalmente en desacuerdo y 5 totalmente de acuerdo). Los valores más elevados en los distintos aspectos evaluados se obtienen en las cuestiones referidas a que la finalidad de los IES es socializadora (puntuación media $=3.8$ ); el Consejo Escolar representa a la comunidad educativa con un papel decisivo en la gestión del centro (puntuación media = 4.1); la financiación de los IES proviene exclusivamente de fondos públicos (media obtenida de 3.8); la investigación es una función a desarrollar dentro del centro de Secundaria (puntuación media $=3.7$ ); la función del profesorado es facilitar los aprendizajes del alumnado (puntuación media $=4.3$ ); el profesor tiene que priorizar su capacitación en la actualización de técnicas y estrategias didácticas de enseñanza/aprendizaje (puntuación media $=4.0$ ); el bagaje sociocultural del alumnado y la propia evolución de la sociedad hacen necesaria la adaptación de la docencia a nuevas formas de aprendizaje (puntuación media $=4.3$ ); la autoevaluación del profesorado tiene repercusiones en la mejora de la docencia (puntuación media $=4.2$ ); en las tareas de docencia el profesorado utiliza las TIC (puntuación media $=3.7$ ); la escuela no es el único lugar donde se produce el aprendizaje y la formación del alumnado sino que su labor se ha de vertebrar con el conjunto de la comunidad local (puntuación media $=4.7$, uno de los valores más elevados). El valor menos elevado se obtiene en la cuestión referida a que el proceso de enseñanza/aprendizaje tiene que basarse principalmente en la clase magistral ya que la puntuación media obtenida es de 1.8.

\subsection{Diferencias de medias en la percepción de la cultura organizacional en función del género}

A continuación se presentan los resultados más relevantes en cada uno de los aspectos o manifestaciones anteriormente señalados en función del género. Para ello sólo se muestran los ítems en los que se encuentran diferencias estadísticamente significativas

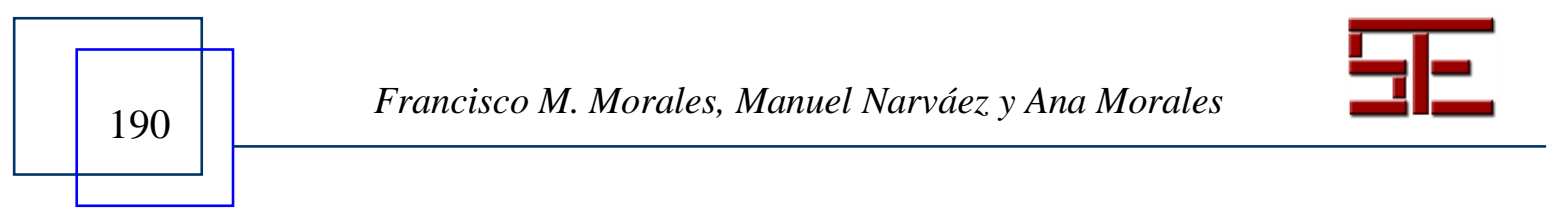




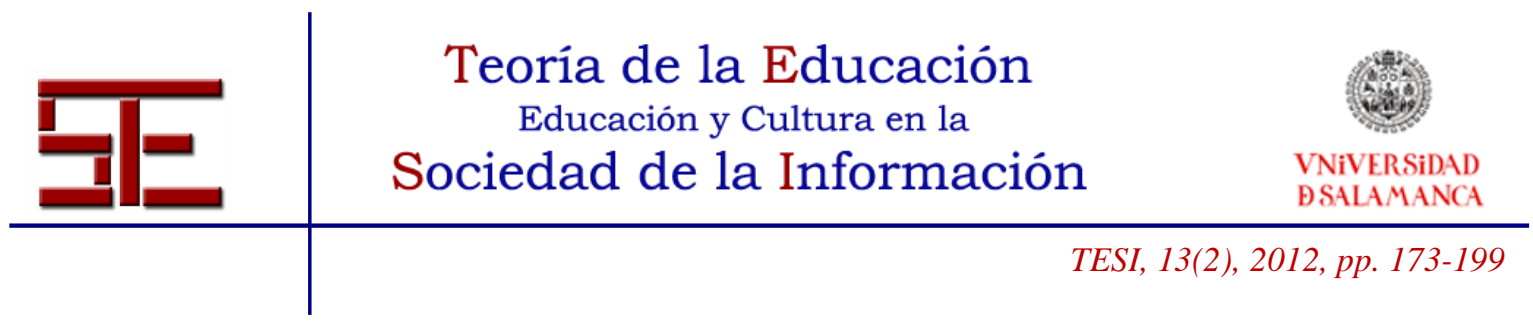

en función del género tras realizar la prueba T de Student (ver Tabla 11). Los resultados demuestran que existen diferencias de género en la percepción de la cultura organizacional de los Centros de Prácticas Externas del Máster de Educación Secundaria en lo que se refiere a aspectos relacionados con las funciones de la Institución, el gobierno de los centros de Educación Secundaria, la financiación, la metodología, el alumnado, la evaluación y las relaciones con el entorno. No se encuentran diferencias estadísticamente significativas en función del género en la percepción de la realidad de los futuros profesores de Educación Secundaria sobre aspectos como la investigación, el perfil del profesorado y la importancia de las Tecnologías de la Información y de la Comunicación. Concretamente, tanto profesores como profesoras perciben negativamente que la finalidad principal de los IES sea de custodia. No obstante, las mujeres obtienen una puntuación media superior en dicho ítem y muestran además mayor grado de acuerdo con la afirmación de que sí se están considerando las necesidades educativas, tecnológicas y culturales al realizar la planificación docente del Centro así como que el número de miembros que componen los órganos colegiados permiten un funcionamiento ágil. Las profesoras muestran menos grado de acuerdo con el ajuste de la asignación presupuestaria a las necesidades reales del Centro. Respecto a la variable metodología, los resultados indican que las profesoras muestran menos grado de acuerdo con el hecho de que el proceso de enseñanza/aprendizaje se base principalmente en la realización de proyectos y que los aprendizajes sean evaluados preferentemente a través de trabajos e informes sobre los contenidos de la asignatura.

Puede destacarse además que las profesoras tienen una percepción más positiva sobre el hecho de que el alumnado recibe formación de los expertos en los institutos en las diferentes materias. Asimismo, también obtienen puntuaciones superiores cuando valoran la participación activa del profesorado en la evaluación externa del centro y la importancia otorgada a que la práctica docente incluya procesos de autoevaluación. Además, aunque ambos géneros informan de la necesidad de acercar la educación a la sociedad mediante la relación de centros educativos con las instituciones/empresas a través de fórmulas como convenios de colaboración, son las profesoras las que obtienen puntuaciones superiores estadísticamente significativas en este ítem (en el que además obtienen una de las medias más elevadas).

Los resultados indican que las mujeres presentan puntuaciones medias más elevadas en la mayoría de las cuestiones referidas a la percepción de la cultura

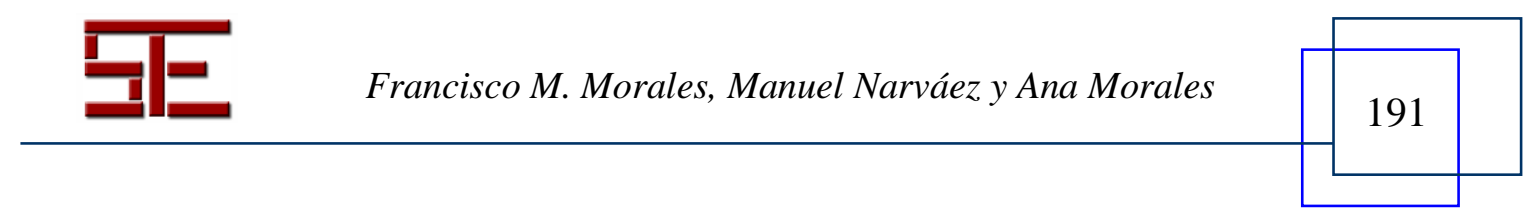




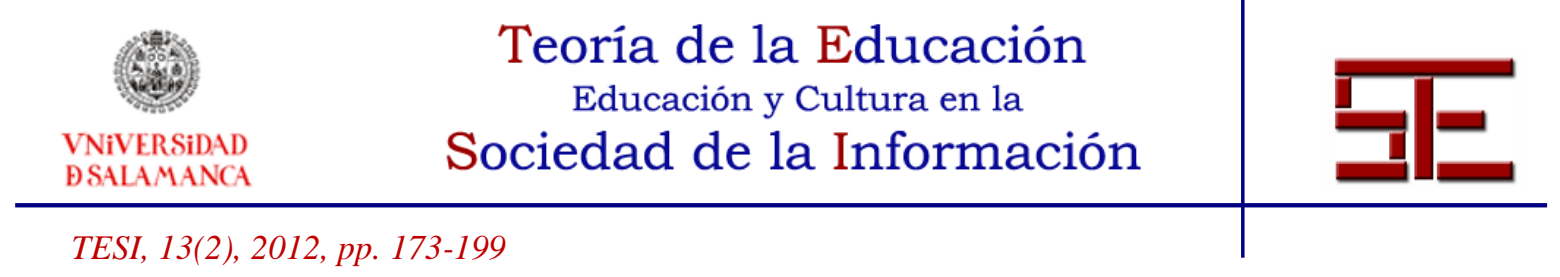

organizacional de los centros de prácticas externas de Educación Secundaria en las que existen diferencias estadísticamente significativas en función del género, es decir, consideran en mayor medida que los hombres, por ejemplo, que la finalidad de los IES es de custodia; que se están considerando las necesidades educativas, tecnológicas y culturales en la planificación docente; el alumnado recibe en los institutos formación de los expertos en las diferentes materias, el profesorado participa activamente en la evaluación externa del centro, y que la práctica docente incluye procesos de autoevaluación. En cambio, los hombres obtienen mayor puntuación media, en comparación con las mujeres, en las cuestiones referidas a que la asignación del presupuesto a los IES está sometida a necesidades reales independientes de los criterios generales establecidos por el conjunto del sistema, que el proceso de enseñanza/aprendizaje tiene que basarse fundamentalmente en la realización de proyectos y que los aprendizajes tienen que evaluarse preferentemente a través de trabajos e informes sobre los contenidos de las asignaturas. De todas las cuestiones que presentan una distribución diferencial estadísticamente significativa en función de la variable género, como se observa en la Tabla 11, el valor inferior con una media de 1.33 por parte de las mujeres se corresponde a la cuestión referida a que la asignación de los presupuestos de los IES está sometida a sus necesidades reales con independencia de los criterios generales establecidos por el conjunto del sistema.

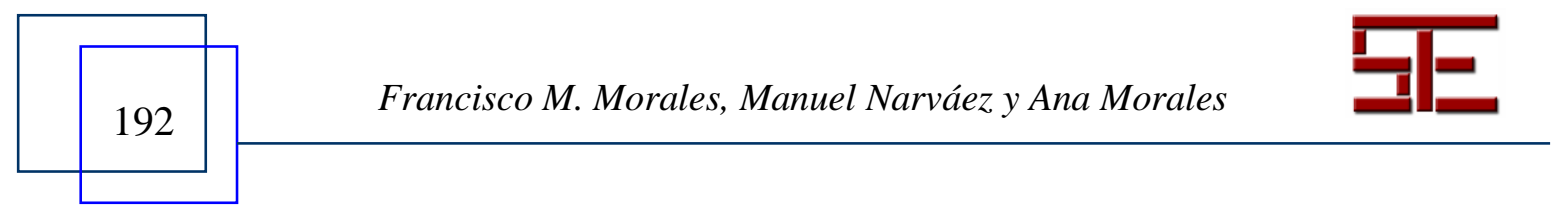




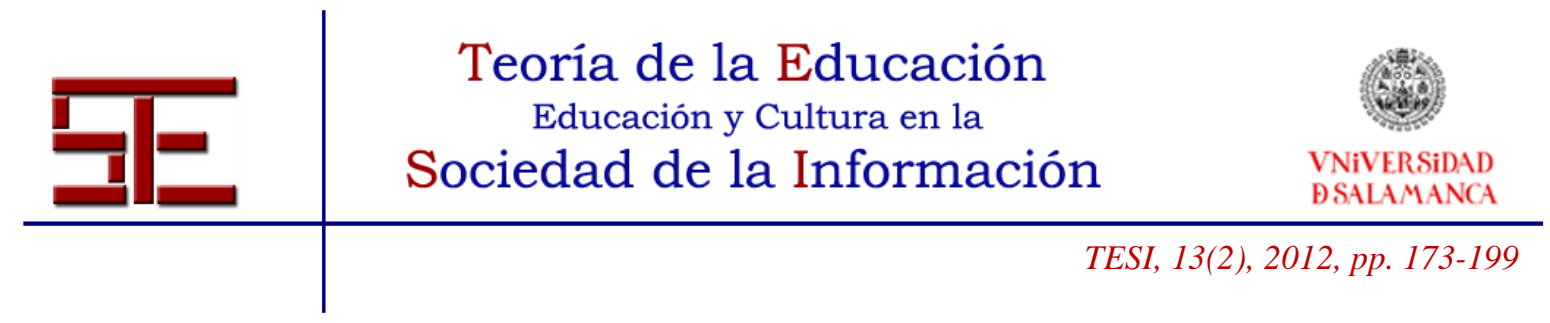

Tabla 11. Diferencia de medias en percepción de la cultura organizacional de los Centros de Prácticas Externas de Educación Secundaria en función del género

\begin{tabular}{|c|c|c|c|}
\hline Ítem & $\begin{array}{c}\text { Hombres } \\
\text { Media (DT) }\end{array}$ & $\begin{array}{c}\text { Mujeres } \\
\text { Media (DT) }\end{array}$ & $\underset{\mathrm{t}}{\mathrm{gl}=55}$ \\
\hline $\begin{array}{l}\text { La finalidad de los IES es de custodia y se } \\
\text { priorizan mecanismos organizativos y } \\
\text { administrativos para llevarla a término }\end{array}$ & $2.16(1.02)$ & $3.60(1.14)$ & $-2.43 *$ \\
\hline $\begin{array}{l}\text { órganos colegiados (claustro, departamento, } \\
\text { consejo escolar...) permite un funcionamiento } \\
\text { ágil }\end{array}$ & $2.66(.88)$ & $4.00(.81)$ & $-2.65^{*}$ \\
\hline $\begin{array}{l}\text { La asignación del presupuesto a los IES está } \\
\text { sometida a sus necesidades reales con } \\
\text { independencia de los criterios generales } \\
\text { establecidos por el conjunto del sistema }\end{array}$ & $2.90(.83)$ & $1.33(.57)$ & $3.04 * *$ \\
\hline $\begin{array}{l}\text { Los aprendizajes tienen que evaluarse } \\
\text { preferentemente a través de trabajos e informes } \\
\text { sobre los contenidos de la asignatura }\end{array}$ & $3.83(.57)$ & $3.00(.80)$ & $2.27 *$ \\
\hline $\begin{array}{l}\text { El alumnado recibe en el instituto formación de } \\
\text { los expertos en las diferentes materias }\end{array}$ & $2.91(.79)$ & $4.00(.00)$ & $-2.67 *$ \\
\hline $\begin{array}{l}\text { El profesorado participa activamente en la } \\
\text { evaluación externa del centro }\end{array}$ & $2.81(.87)$ & $4.00(.00)$ & $-4.68 * *$ \\
\hline $\begin{array}{l}\text { La práctica docente incluye procesos de auto- } \\
\text { evaluación }\end{array}$ & $3.50(.79)$ & $4.50(.57)$ & $-2.71 *$ \\
\hline $\begin{array}{l}\text { La relación de los centros educativos con las } \\
\text { instituciones/empresas a través de convenios de } \\
\text { colaboración se ve como una fórmula } \\
\text { interesante que acerca la educación a la } \\
\text { sociedad }\end{array}$ & $3.58(.51)$ & $4.67(.58)$ & $-3.20 * *$ \\
\hline
\end{tabular}

Significación estadística. ${ }^{*} p<0.05 ; * * p<0.01$

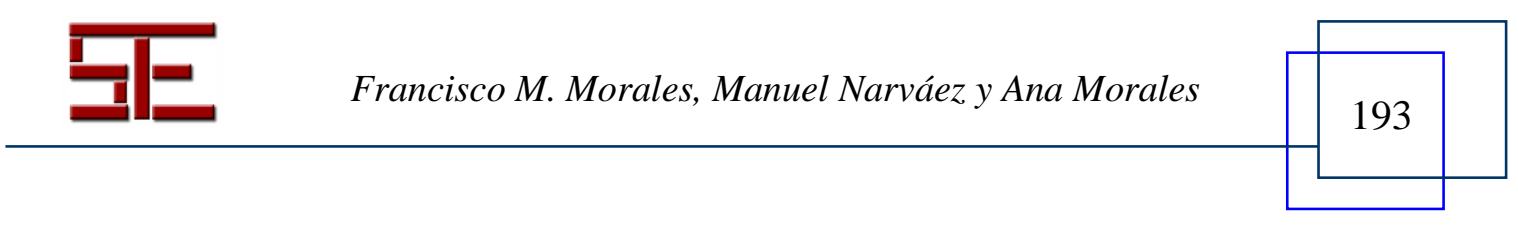




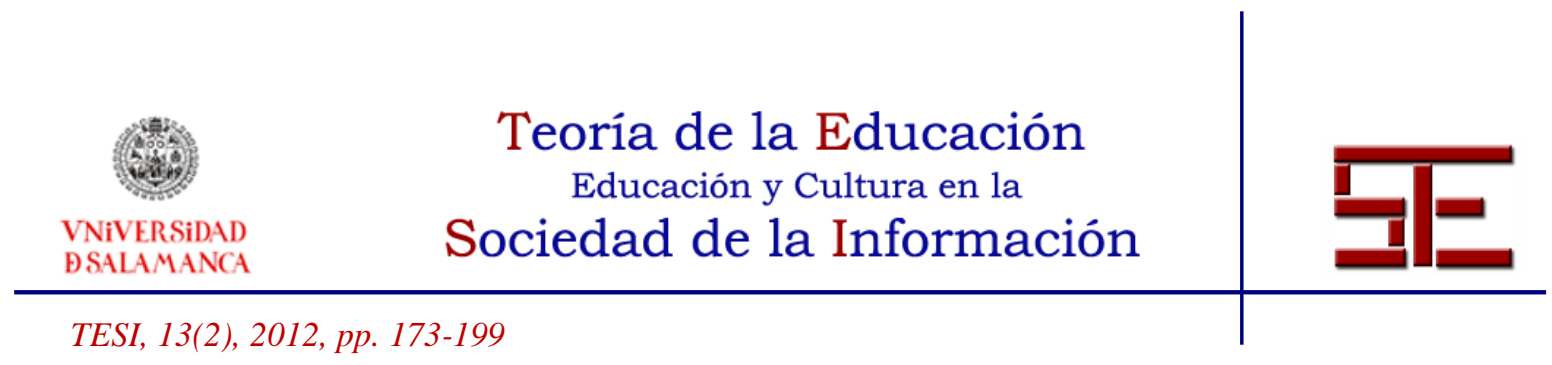

\section{4.- DISCUSIÓN}

La educación secundaria es uno de los niveles educativos que no siempre ha estado bien definido quizás al tratar de reflejar los cambiantes valores de la sociedad y ser la principal oportunidad para alcanzar las bases de una sólida formación cultural integral y sistémica en humanidades, ciencia y tecnología. En este sentido, el estudio de la percepción de los futuros docentes sobre la cultura organizacional de los centros de prácticas externas de Educación Secundaria es muy interesante ya que, como se plantea en investigaciones recientes (Coll, 2010; Feito, 2010; Pérez, 2010), este tema forma parte de un proceso de cambio en la formación hacia la calidad de la educación. Los datos obtenidos en el presente estudio resultan de interés para conocer y evaluar de forma más precisa cómo perciben la cultura organizacional los futuros docentes actualmente estudiantes del Máster Universitario en Profesorado de Educación Secundaria Obligatoria y Bachillerato, Formación Profesional y Enseñanza de Idiomas.

En la misma línea, como encuentran otros estudios (Guil, 1998; Marcelo, 1987; Otero-López et al., 2009), conocer, evaluar e investigar sobre aspectos relacionados con la cultura organizacional resulta relevante para optimizar las estrategias y el desarrollo de las acciones que ha de acometer el profesorado de los Centros de Enseñanza Secundaria para mejorar el proceso de enseñanza/aprendizaje, para el buen funcionamiento de los centros y la consecución de los objetivos planificados.

La cultura organizacional es un constructo complejo que algunos autores en nuestro país (Pérez Martínez, 2009) definen del siguiente modo: "Cultura son las creencias, ya sean inventadas, desarrolladas o descubiertas, que los grupos juzgan como válidas y le permiten adaptarse al entorno e integrarse internamente, así como que son enseñados como el modo correcto de percibir, pensar y sentir sus problemas" (p. 21). Para Gairín (2003) el hablar de cultura organizacional implica el reconocimiento que en el sí de cada centro existe una realidad organizativa, formas de interrelación, prácticas de actuación y sistemas de creencias, tradiciones, valores y símbolos que conforman una determinada realidad. Otros autores (Armengol, 2001) plantean que la cultura organizacional escolar puede definirse como el "Conjunto de normas, creencias y valores compartidos que constituyen el marco interpretativo de referencia e identidad (símbolos y significados) del centro; son aprendidos y/o compartidos por el grupo" (p.32). Para Rivas (2003) implica el estar atentos a los procesos políticos /sociales y

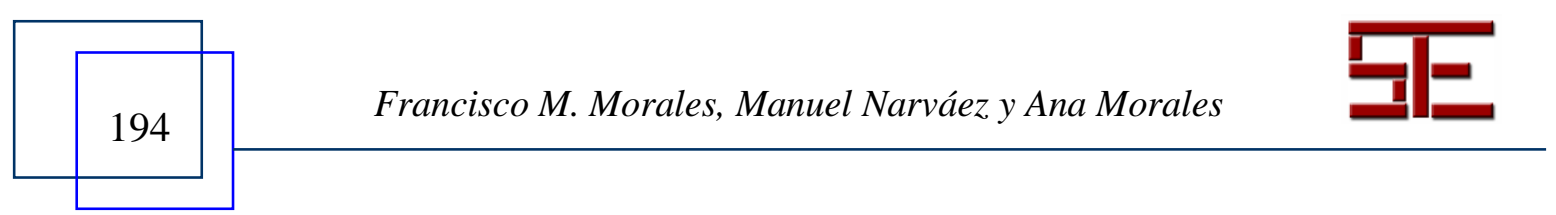




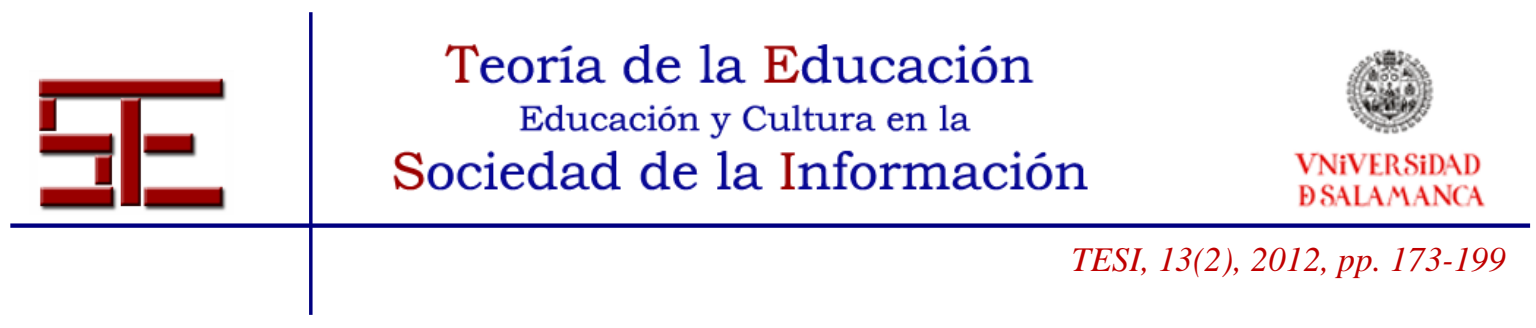

significados que generan las acciones que tienen lugar en el interior de los centros educativos. En otras investigaciones (Martín, 2003) se plantea también que la cultura lo impregna todo, son las formas de vida e influye en las relaciones sociales. Estos aspectos están presentes de algún modo en el cuestionario empleado para evaluar la cultura organizacional en esta investigación.

De todas estas definiciones se desprende que parece existir un amplio acuerdo en que la cultura organizacional implica un sistema de significados compartidos entre sus miembros (ideas, valores y creencias) que distingue a una organización de otra y también puede ser analizada desde la perspectiva que observa directamente el comportamiento, lenguaje y uso de los objetos materiales en los miembros de la institución. Es importante señalar que, precisamente en el cuestionario empleado para evaluar la percepción de la cultura organizacional en este estudio, están presentes todas estas manifestaciones o aspectos relevantes para identificar la cultura organizativa en los Centros de Educación Secundaria planteados en dichos estudios consolidados señalados anteriormente (por ejemplo, Armengol) tales como las funciones de la institución, gobierno de los centros, financiación de los centros, investigación, perfil del profesorado, metodología, alumnado, evaluación, Tecnologías de la Información y de la Comunicación y relaciones con el entorno. En ese sentido, del análisis de los resultados pueden destacarse, entre otras muchas, las siguientes conclusiones: a) Los futuros docentes priorizan la finalidad instructiva y socializadora de los IES enfatizando en primer lugar los aspectos relacionados con la educación en valores. Este dato es congruente con lo que plantean algunos autores (Hernández y Sancho, 1989) de que la evolución de nuestro sistema educativo requiere por parte de los IES una función más social y comprensiva y no solo instructiva. Subyace una transformación de la función profesional del docente que también se señala relevante para formar ciudadanos europeos. De hecho, en el ámbito universitario también se plantea ya que una de las competencias transversales para fomentar son las sociales y ciudadanas, siendo la eticidad de la ciudadanía objeto del binomio enseñanza/aprendizaje; b) Perciben que el Consejo Escolar tiene un papel decisivo en la gestión del centro cuya financiación proviene prácticamente en su totalidad de fondos públicos, de todos los contribuyentes; c) Reconocen que la investigación es una de las funciones que es necesario desarrollar en los IES y la importancia de asumir un modelo reflexivo para facilitar los aprendizajes del alumnado y contribuir a la mejora de la sociedad; d) Entienden que el proceso de enseñanza aprendizaje ya no puede basarse solo en la clase magistral y que el profesorado debe actualizar sus técnicas y estrategias didácticas de enseñanza/aprendizaje fomentando un trabajo en grupos colaborativos y cooperativos;

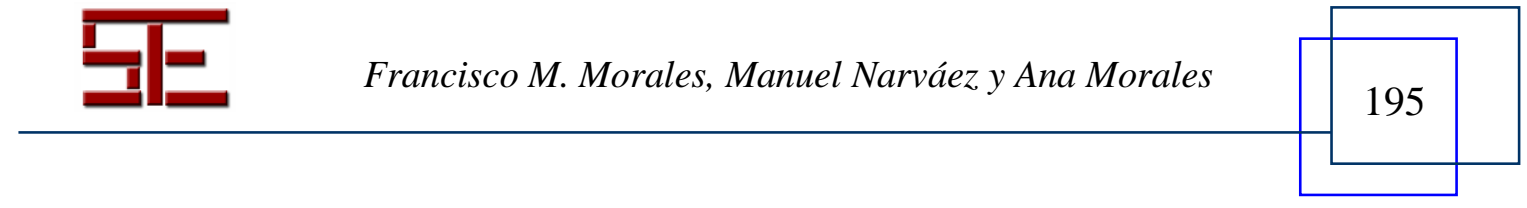




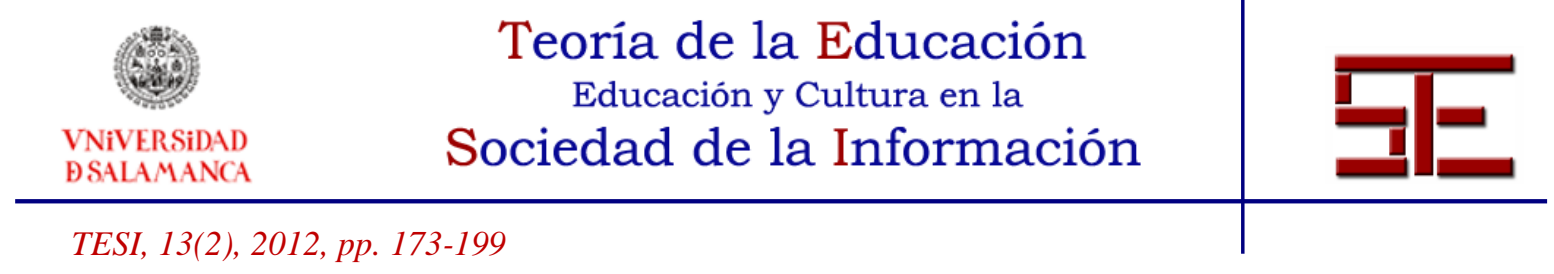

e) Plantean la importancia de considerar el rol activo del alumnado en su proceso de aprendizaje y el rol facilitador del profesorado donde entienden además la importancia de los principios psicopedagógicos de atención a la diversidad; f) Consideran que el proceso de evaluación puede contribuir a la mejora de los centros e incluso, como señalan algunos autores en la actualidad (con sus discrepancias), entienden que la autoevaluación del profesorado puede tener repercusiones en la mejora de la docencia; g) Con respecto a las TIC valoran que las aulas de informática están adecuadas para la docencia y perciben buena predisposición hacia el uso de las TIC en la docencia. Este dato es satisfactorio ya que en el nivel de educación secundaria la Ley Orgánica de Educación (LOE, 2006) establece entre las competencias básicas para desarrollar, el tratamiento de la información y la competencia digital que se define como "disponer de habilidades para buscar, obtener, procesar y comunicar información, y para transformarla en conocimiento". Existen trabajos actuales que buscan conocer las posibilidades de las herramientas digitales para gestionar el plan de prácticas realizado por el alumnado en los centros de secundaria (Pérez, 2010); h) Asumen una perspectiva sistémica respecto al proceso educativo considerando necesaria la vertebración de la labor educativa de la escuela con el conjunto de la comunidad local (asociaciones, empresas, comunidad local, ONGs, etc). Es grato comprobar que consideran bastante enriquecedor el intercambio de experiencias entre el centro y su entorno.

El análisis de los resultados demuestra que existen diferencias en función del género en la percepción de los futuros docentes sobre la cultura organizacional de los Centros de Prácticas Externas del Máster de Educación Secundaria en lo que se refiere a algunos aspectos relacionados con las funciones de la institución, el gobierno de los centros, la financiación de los centros públicos de Secundaria, la metodología, el alumnado, la evaluación y las relaciones con el entorno. Los datos indican que los hombres consideran en mayor medida que las mujeres y por este orden de importancia que el proceso de enseñanza aprendizaje tiene que basarse en la realización de proyectos, que los aprendizajes tienen que evaluarse preferentemente a través de trabajos e informes sobre los contenidos de la asignatura y que la asignación del presupuesto de los IES está sometida a sus necesidades reales con independencia de los criterios generales establecidos por el conjunto del sistema. No obstante, es necesario seguir profundizando en el papel del género, edad, niveles de experiencia profesional, área de conocimiento y especialidad concreta a la que nos referimos en futuros estudios.

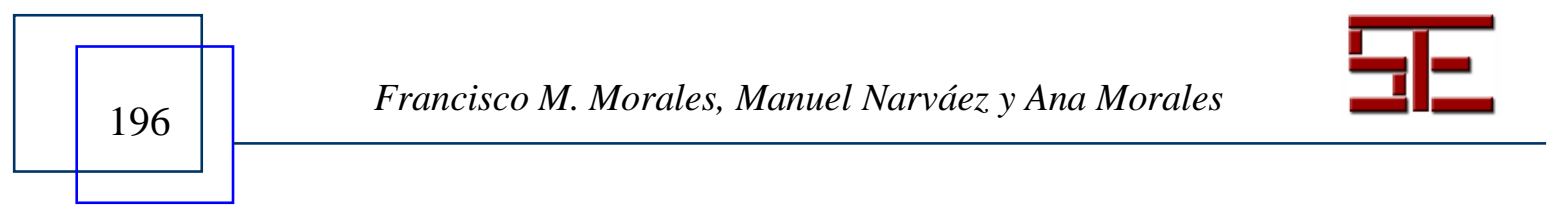




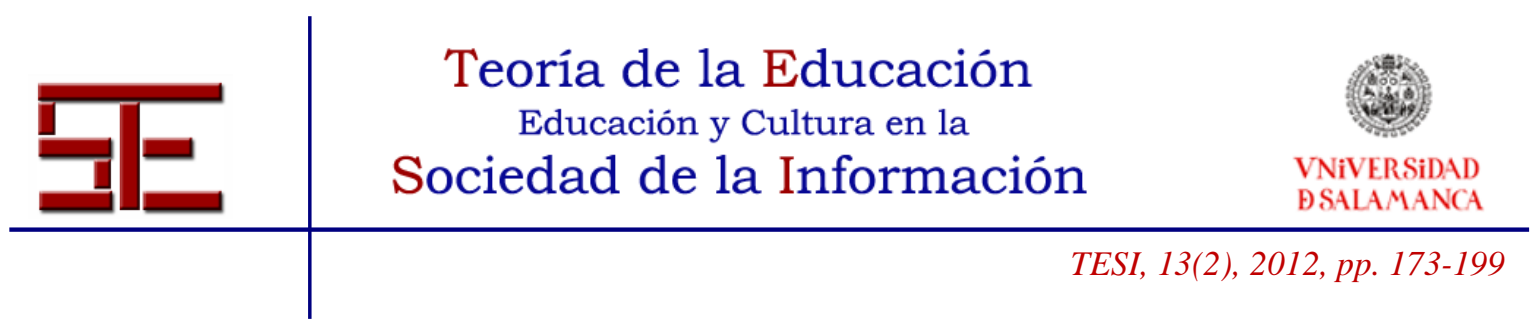

Aun con dichas limitaciones, este estudio permite una evaluación exhaustiva de la cultura organizacional, que puede contribuir de algún modo a una reflexión prospectiva sobre diversos aspectos de la política educativa en este ámbito. En coherencia con otros autores (Coll, 2010; Feito, 2010; Rivera, 2000) se considera que el conocimiento de las características de la cultura organizacional de los Centros de Educación Secundaria forma parte de un proceso de cambio en beneficio de una mayor calidad educativa. Precisamente, otras investigaciones actuales (Pérez, 2010) indican que entre los criterios epistemológicos fundamentales de la propuesta de sistematización en el prácticum del Máster de Educación Secundaria está el relacionado con la propia comprensión de la experiencia del prácticum: lo que vemos, escuchamos, hacemos y vemos hacer constituye una práctica social situada, en la que diferentes sujetos ponen en la acción de enseñanza y aprendizaje comprensiones diferentes del mundo, y en esa interacción compleja de interpretaciones culturales y sociales se inscribe el proyecto personal en el prácticum. Por tanto, evaluar las percepciones de la cultura organizacional resulta necesario también para la formación del profesorado, para reflejar una visión más coherente de la Educación Secundaria que puede ser útil tanto para los futuros docentes como para el profesor en ejercicio que desee potenciar su desarrollo profesional.

Se concluye señalando cómo este estudio permite analizar las actitudes y opiniones del profesorado principiante hacia el funcionamiento de un Centro de Secundaria permitiendo favorecer el conocimiento y toma de conciencia sobre las mismas para optimizar las estrategias y expectativas profesionales adecuadas y contribuir a la mejora del proceso de enseñanza/aprendizaje al dotarlo de una mayor armonía con la realidad y condiciones en las que se ha de trabajar que pueden tener consecuencias directas en la formación del alumnado.

Agradecimientos: Agradecemos a los revisores las sugerencias realizadas para la mejora de este trabajo y al alumnado/profesorado que han participado en este estudio.

\section{5.- BIBLIOGRAFÍA}

Armengol, C. (2001). La cultura de la colaboración. Reto para una enseñanza de calidad. Madrid: La Muralla.

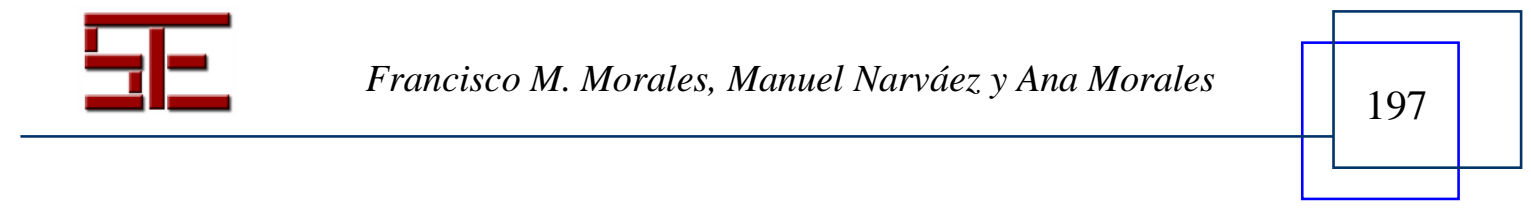




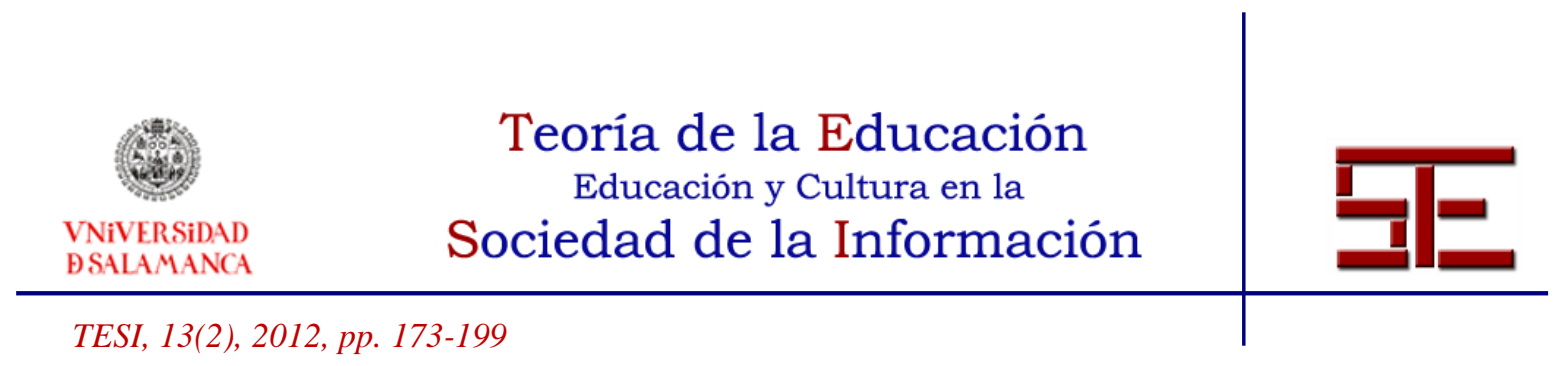

Coll, C. (2010). Desarrollo, aprendizaje y enseñanza en la educación secundaria. Barcelona: Graó.

Feito, R. (2010). Sociología de la educación secundaria. Barcelona: Graó.

Gairín, J. (2003). Les relacions personals en l'organització. Organització i gestió 14. Grup 1. Barcelona: ICE de la UAB.

Guil, R. y Mestre, J. (1998). Violencia escolar: su relación con las actitudes sociales del alumnado y el clima social del aula. Revista Electrónica Iberoamericana de Psicología Social (REIPS). Extraído el 2 de febrero, 2011, de www.psico.uniovi.es/REIPS/v2n1/art.1.html.

Hernández, F. y Sancho, J. M. (1989). Para enseñar no basta con saber la asignatura. Cuadernos de Pedagogogía. Barcelona: Laia.

Marcelo, C. (1987). El pensamiento del docente. Barcelona: CEAC.

Martín, M. (2003). Un clima social de aula para el desarrollo cultural y 'nido' de relaciones humanas. Aula como clima cultural y vínculo social. Alcalá de Henares: Universidad de Alcalá.

Otero-López, J., Castro, C., Villardefrancos, E. \& Santiago, M. J. (2009). Job dissatisfaction and burnout in secondary school teachers: student's disruptive behaviour and conflict Management examined. European Journal of Education and Psychology, 2, 99-111.

Pérez, A. (2010). Aprender a enseñar en la práctica: Procesos de innovación y prácticas de formación en la educación secundaria. Barcelona: Graó.

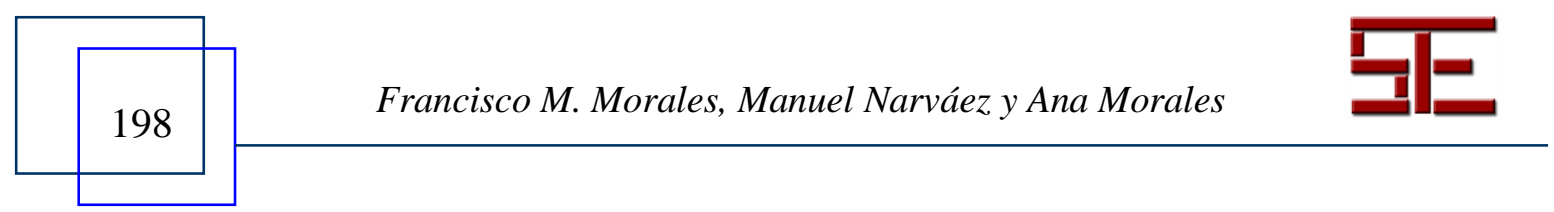




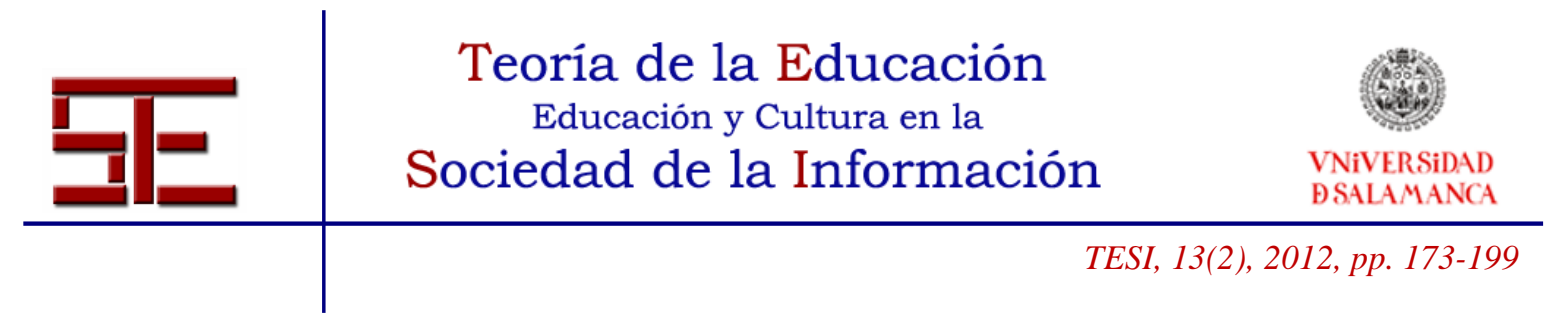

Pérez Martínez, A. (2009). La cultura organizacional, algunas reflexiones a la luz de los nuevos retos. Madrid: Escuela Universitaria de Estudios Empresariales.

Rivas, J. I. (2003). La perspectiva cultural de la organización escolar: marco institucional y comportamiento individual. Educar 31. Málaga: Universidad de Málaga, 109-119 [PDF]. Extraído el 2 de febrero, 2011, de www.bib.uab.es/pub/educar/0211819Xn31p109.pdf.

Rivera, M. (2000). El clima organizacional de unidades educativas y la puesta en marcha de la reforma educativa [en línea]. Tesis doctoral de la Universidad de Antofagasta - Chile. Dirección de Graduados de la Facultad de Educación y Ciencias Humanas. www.reduc.cl/reduc/rivera.PDF.

Tomás, M., Mas, A. y Jofre, G. (2006). Estudio sobre el clima y la cultura en los centros de Educación Secundaria. Informe de investigación. $\mathrm{N}^{\circ}$ expediente 2004ARIE0026.

Para citar el presente artículo puede utilizar la siguiente referencia:

Morales Rodríguez, F.M., Narváez Peláez, M. A. y Morales Rodríguez, A. M. (2012). Percepciones de los futuros docentes sobre la cultura organizacional de los centros de prácticas externas de Educación Secundaria. Revista Teoría de la Educación: Educación y Cultura en la Sociedad de la Información. 13(2), 173-199 [Fecha de consulta: $\mathrm{dd} / \mathrm{mm} / \mathrm{aaaa}]$.

http://campus.usal.es/ revistas_trabajo/index.php/revistatesi/article/view/9004/9249

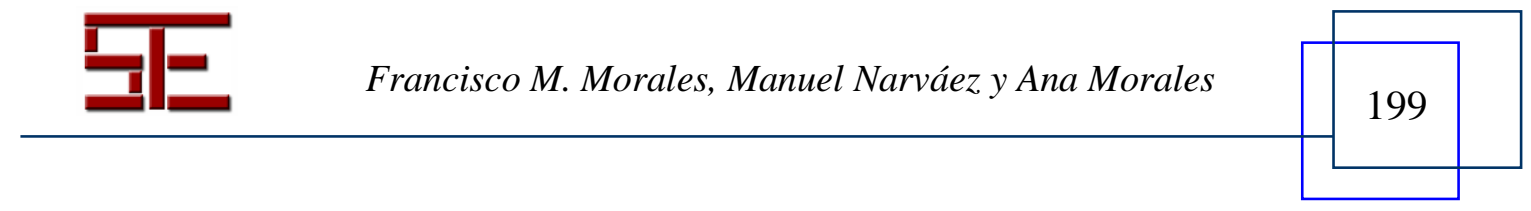

